\title{
دور الغزالي في ترسيخ الاتجاه النقدي للفلسفة المشّائيّة في الفكر الإسلامي
}

\section{* بدران مسعود بن لحسن}

$$
\begin{aligned}
& \text { الملخص } \\
& \text { يهدف هذا البحث إلى إعادة النظر في المقولات المغلوطة عن الغزالي، وذلك بإبراز جهده التجديدي في تثبيت }
\end{aligned}
$$

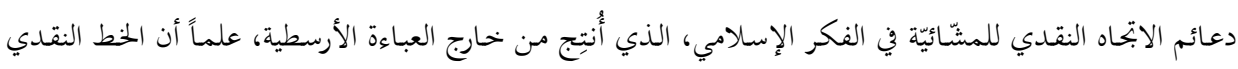

$$
\begin{aligned}
& \text { الذي سلكه الغزالي توجَّه بالنقد إلى أفكار الفلاسفة السابقين، ولا سيما أصحاب المدرسة المشّّئيّة؛ إذ عمل على فهم }
\end{aligned}
$$

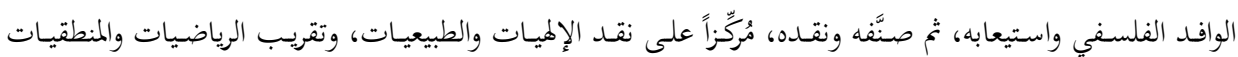

$$
\begin{aligned}
& \text { والتجريبيات. } \\
& \text { ويُبرِز البحث حقيقة أن الغزالي يُمثّلّ الاستقلال الفكري، والمثاقفة البصيرة الواعية التي تتخذ لنفسها موقفاً نقدياً، } \\
& \text { تقبل بواسطته ما تراه موافقاً للحقيقة، وترفض ما تراه غير ذلك، من دون عقدة نقصٍ أو تماهٍ مع الآخر. } \\
& \text { الكلمات المفتاحية: الغزالي، الاتحاه النقدي، المشّائيّة، الإلهيات، الميتافيزيقا، الطبيعيات، المنطقيات، المثاقفة. }
\end{aligned}
$$

\section{The Role of al-Ghazali in Establishing the Critical Approach of the Peripatetic Philosophy in Islamic Thought}

\section{Badran Masoud Benlahsen}

\begin{abstract}
This paper focuses on revising the false statements about al-Ghazali by highlighting his renewal efforts in deepening the critical trend in Islamic philosophy, which was produced from outside the Aristotelian paradigm. This trend which alGhazali was one of its pioneers, directed its critics to the ideas of former philosophers, especially the Muslim Aristotelian School. He then categorized and criticized the Aristotelian school, focusing more on the critique of its metaphysics and cosmology, while accepting mathematics, logic and experimentation.

The paper also shows that al-Ghazali presents a model of an intellectual independence, a conscious acculturation, which takes a critical stance and accepts what he sees true and rejects what he sees false, without feeling inferior towards the other.

Keywords: al-Ghazali, Critical trend; Aristotelianism; Metaphysic; Cosmology; Logic; Acculturation.

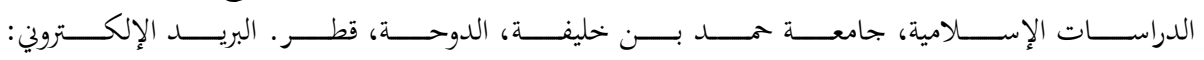

$$
\begin{aligned}
& \text { bbenlahcene@hbku.edu.qa }
\end{aligned}
$$$$
\text { * دكتوراه في دراسات الحضارة والفلسفة، جامعة بوترا، ماليزيا، ع . . بم، أستاذ مشارك في برنامج مقارنة الأديان، كلية }
$$

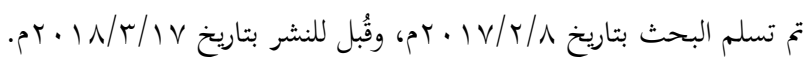




\section{مقدمة:}

عاش الإمـام الغزالي عصراً زاخراً بالتيارات الفكرية والسياسية المتلاطمة، وشـارك في

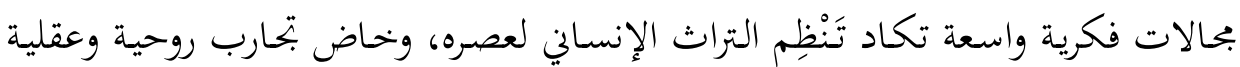

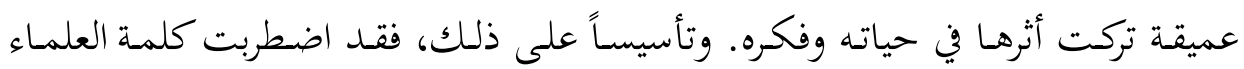

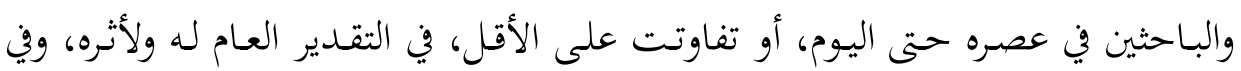

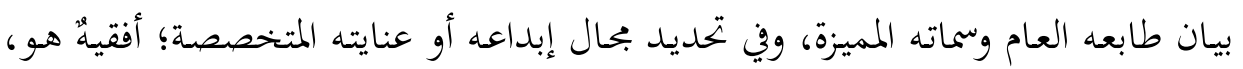

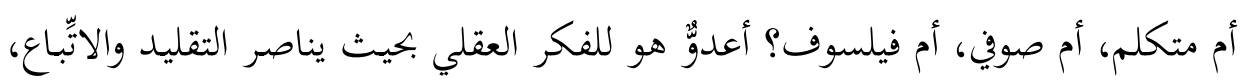

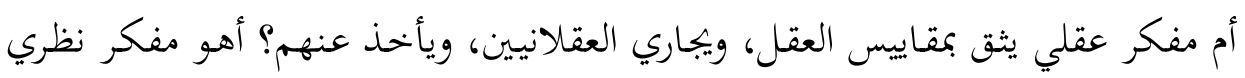

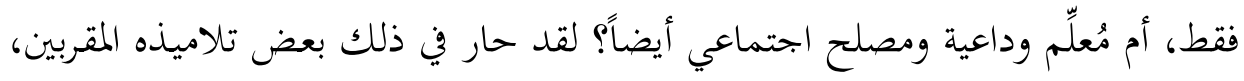

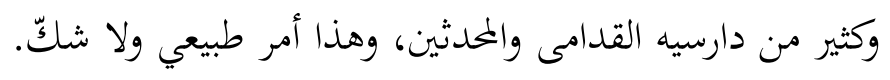

ولهذا سـاد في أوسـاط أغلب البـاحثين العرب أن الغزالي كـان مِعْوَل هـدم للفلسفة؛

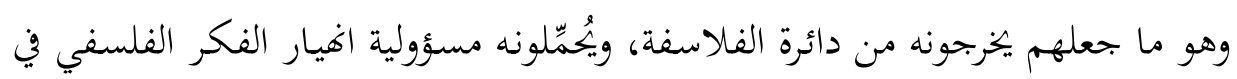
العالم الإسلامي، ويَعزون إليه سبب التراجع الحضاري الذي شهدته الأُمَّة الإسلامية. لقد سادت هذه النظرة السطحية التي تعتمد على قراءات بجزيئية اختزالية لأفكار

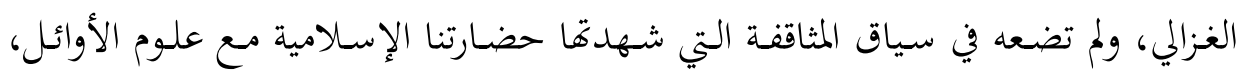

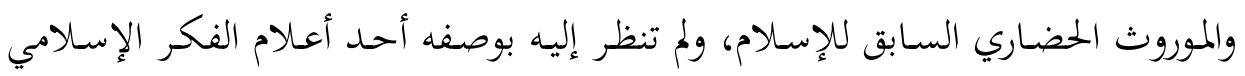
الذين مارسوا نوعاً من المثاقفة الفلسفية مع التراث اليوناني.

ومُّاّ لا شكّ فيه أن الغزالي تناول بالنقد أفكار الفلاسفة السابقين، ولا سيما أتباع

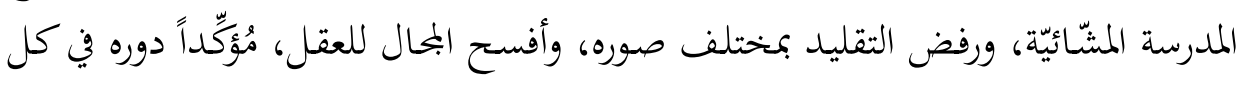

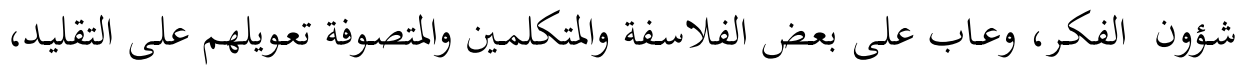

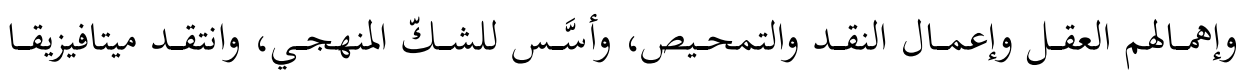

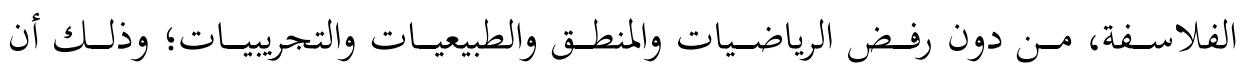

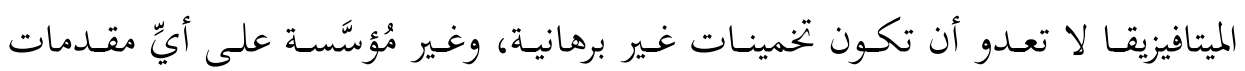


وليس هدفنا في هذا البحث هو الدفاع عن الغزالي من منتقديه أو نقد تُمُجّديه، وإنما

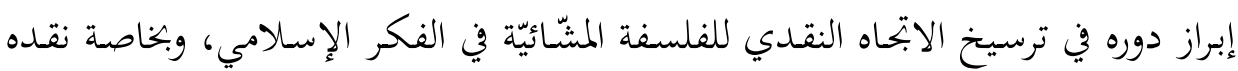
للإلهيات المشّيائية، وقبوله للرياضيات والمنطق.

ولذلك، يتناول البحث مسألة دخول الفلسفة اليونانية حقل المعرفة الإسلامية، ثم النظر في مكانـة الغزالي وأهميـة دراسـة منتجـهـ الفكـري، ثم تحليـل عملـه النقـــي المتعلق

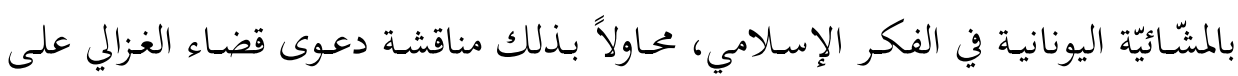
الفلسفة وإبطالها، وبيان أهمية الجهاد النقدي الذي قام به، وموقفه من الموروث الفلسفي

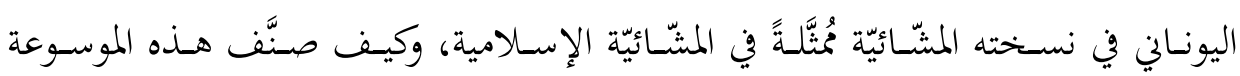
الفلسفية إلى أقسام بحيث رفض بعضها، وقبل أُخرى، وعَدَّ بعضاً آخرَ لا يحتاج ردّاً أو قبولاًا.

ولعل هـا يُمثّل أحسد أهداف هـذا البحث مـن النظر في رائق نقد الفكر الإسلامي

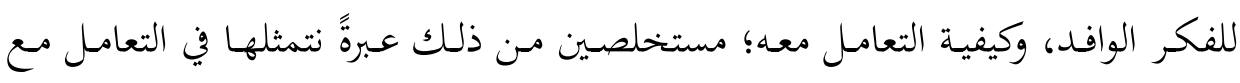
الموروث الوافد علينا في هذا العصر.

\section{أولاً: دخول الفلسفة حقل المعرفة الإسلامية}

تُعَدُّ الفلسفة أُمَّ العلوم، وأُولى المعارف التي وصلت إلى المحال المعريف الإسـلامي عن

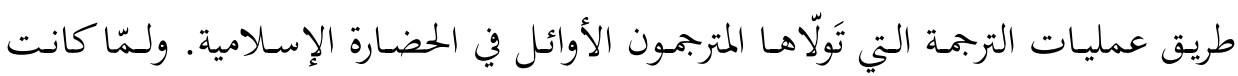

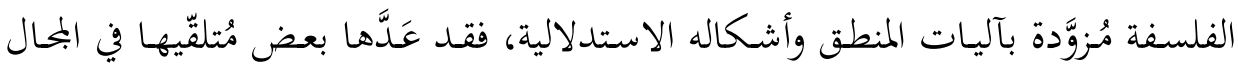

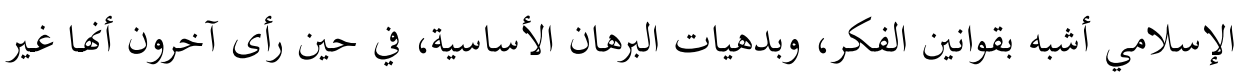

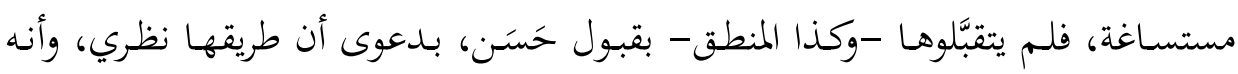

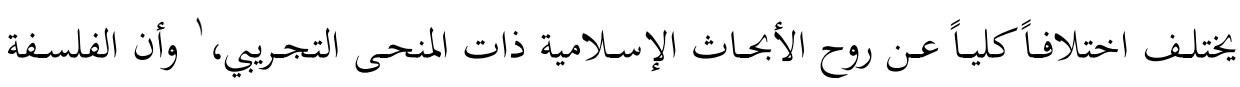

' النشار، علي سامي. منـاهج البحث عند مفكري الإسلام واكتشـاف المنهج العلمي في العالم الإسلامي،

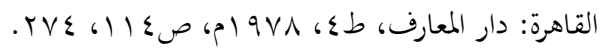


اليونانيـة إنما صـدرت في نشـأهما عـن روح دينيـة مخالفـة لـرؤيتهم الدينيـة الإسـلامية، وأن ميتافيزيقاهم مخالف في جوهره لميتافيزيقا اليونان.

والحقيقة أن طيف الفلسفة والمنطق قد امتد ليشمل مختلف العلوم، مُركّزًاً على منهج

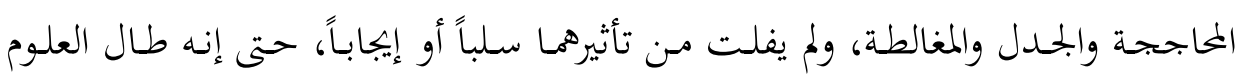

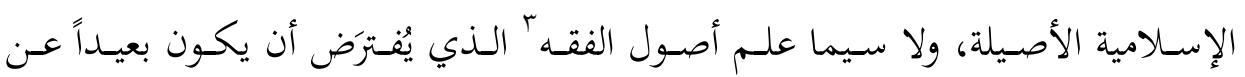

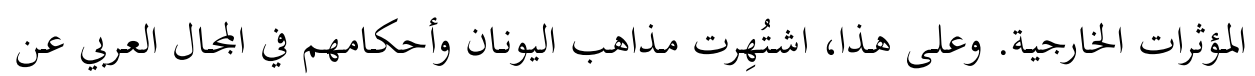
طريق الفلسفة والمنطق، واختلط الفكر الهيليني بالفكر الإسلامي، وكثرت كتب وعتب المنطق، مثل: كتب البرهان، والخطابة، والشعر، والجحل، واخطي، والسفسطة.

ولمّا كانت هذه الكتب تحمل في جوهرها روح حضارة اليونان وعلمهم وفلسفتهم، فقد ثار نقاش حاد في الوسط المعرفي الإسلامي عن هذا الوافد الجديد، وعن صلاحيته،

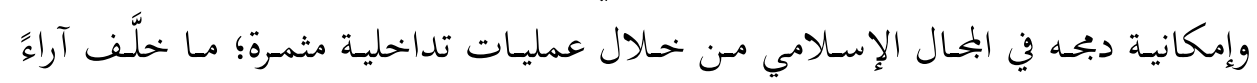

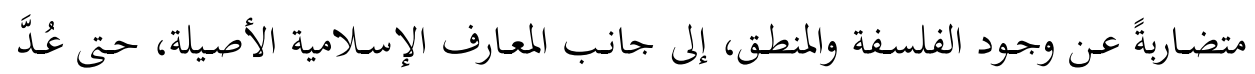
المنطق والفلسفة اليونانيان فننة حقيقية بين علماء الإسلام.

وبتحدر الإشارة إلى أن عملية نقل التراث الفلسفي اليوناني إلى المحال المعرفي الإسلامي

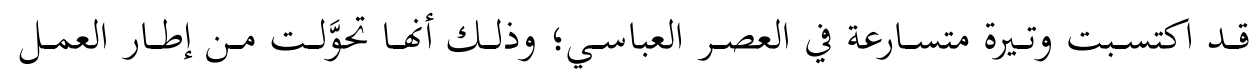

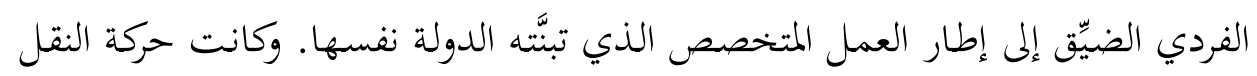

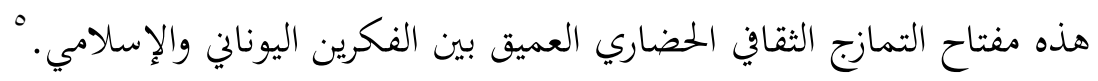
وفي هذا السياق، فبإن دخول الفكر الفلسفي اليوناني إلى البحال الإسلامي أحسث

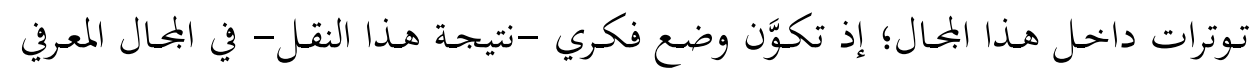

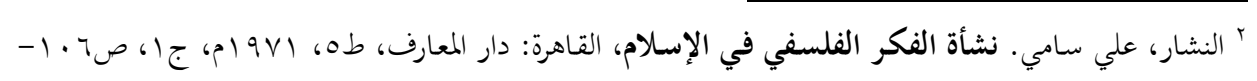
r ابن حزم، أبو محمد علي. الثقريب لحسد المنطق، تحقيق: أحمد المزيدي، بيروت: دار الكتب العلمية، د.ت، ؛ همام، محمد. أثر الفلسفة والمنطق في العلوم الإسلامية. انظر الموقع الإلكتروين لشبكة الفكر المعاصر: - http://fikrweb.net/news48.html • المرجع السابق. 
الإسـالامي؛ ظـاهره التمـازج بـين فكـرين، وباطنسه ومسـتقبله الاصـطدام بـين مـرجعيتين

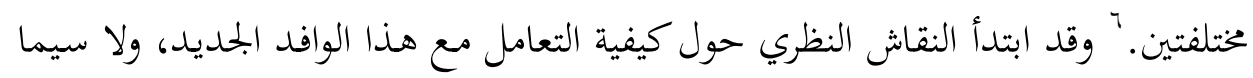

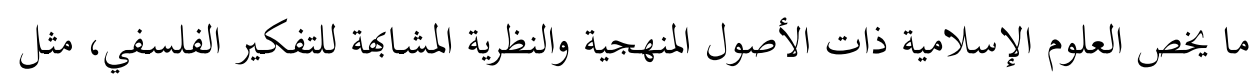
علم الكام الذي هو بحـث فلسفي في جوهره، لكنه لاهوتي بحسب تصنيف الفلسفة الإنة

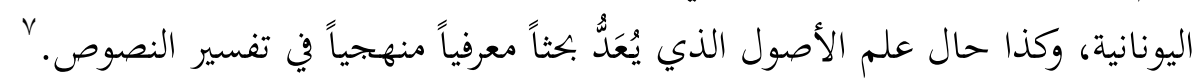
تم إن الفلسفة اليونانية وصلت العرب ممتزجةً، شاملةً معارف أُخرى، مثل: الآداب،

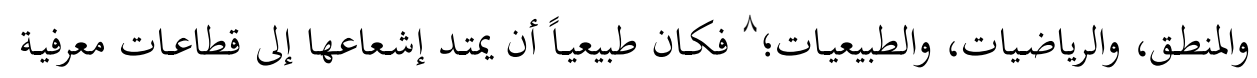

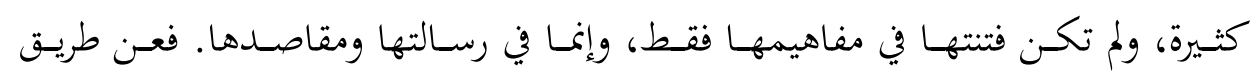

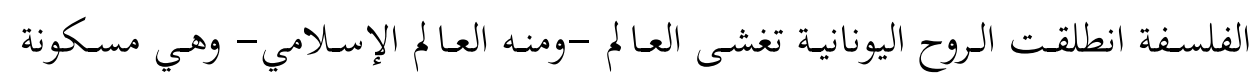

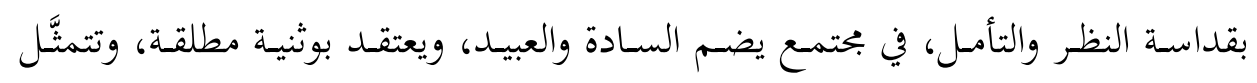

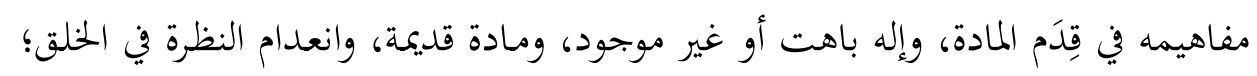

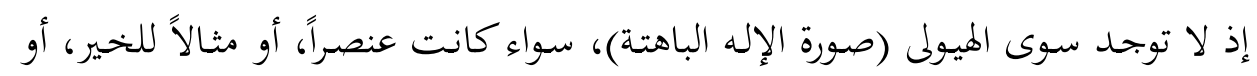

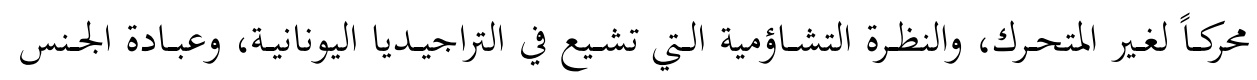
والنوع.

وعلى هـا الأسـاس، فقد ارتفع البنيان الفلسفي اليوناني، الذي أريد له التدويل في

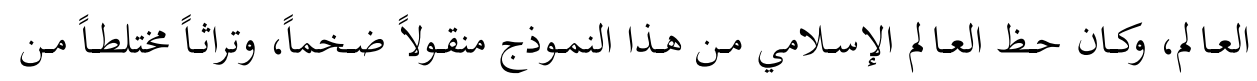

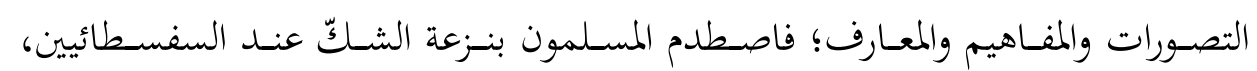

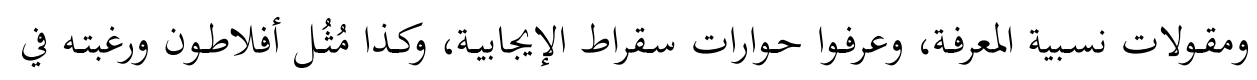
" المرجع السابق.

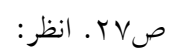

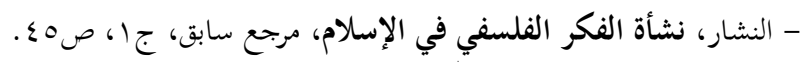

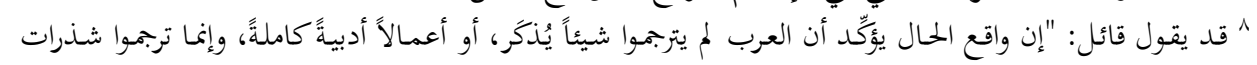

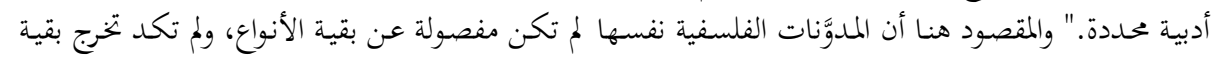

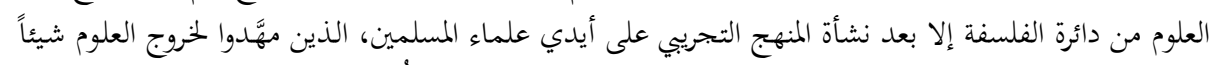

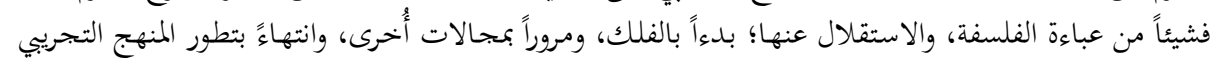
الحديث واستقلال العلوم. 
العودة إلى روح الحضارة اليونانية؛ فقد تردَّد بين الكم والكيف، وجمع بين الجحل الصاعد الحدال

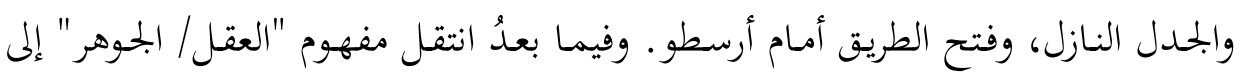
البحال المعرفي الإسلامي.

إذن، فنحن أمام معارف أجنبية دخيلة اصطدمت بمنهج موجود في الداخل (أي في

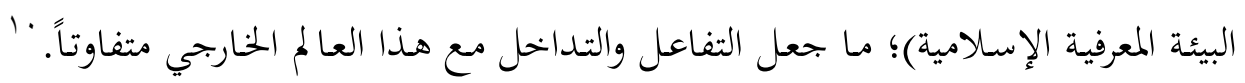

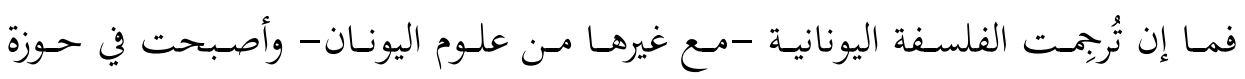

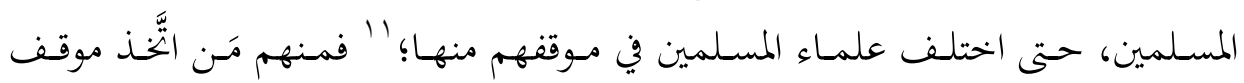

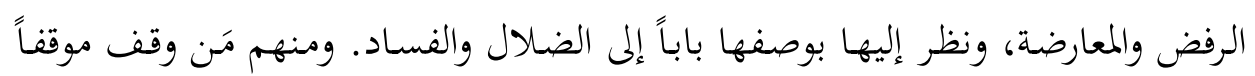

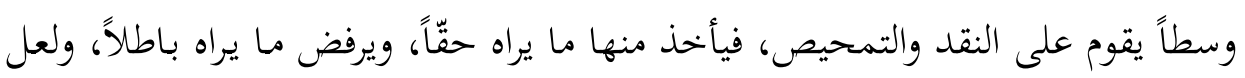
هـا هو موقف المعتزلة وكثير مـ الأشـاعرة؛ فقد اعترض عليها أئمة المعتزلة مـن أمثال:

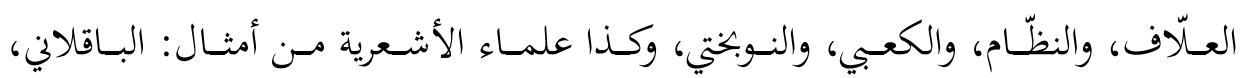

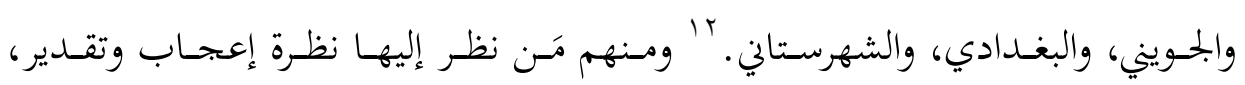

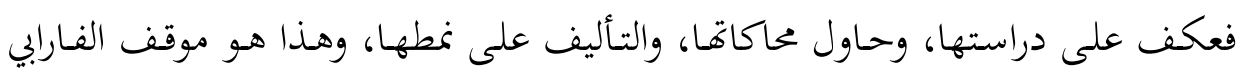
وابن سينا ومَن جاء بعدهما.

ولعل ممن توسَّط في الموقف، وعمل على نقـد المنتج الفلسفي المشائي وتمحيصـه،

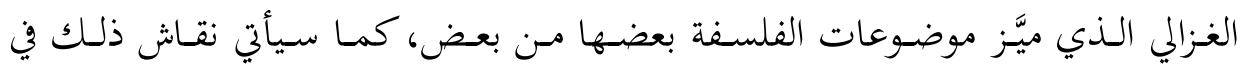
فقرات البحث المقبلة عند بيان نقده التفصيلي لموضوعات الفلسفة وبحالاتما. غير أن مـا يمكـن تأكيده هـو أن هـا الملد الفلسفي لم يكن يتحرك داخل حضـارة

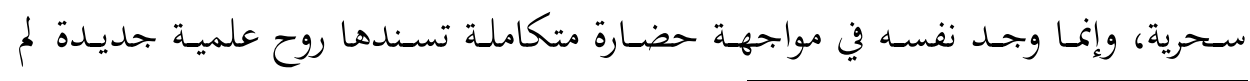
" النشار، مناهج البحث عند مفكري الإسلام واكتشاف المنهج العلمي في العالم الإسلامي، مرجع سابق، • أهمام، أثر الفلسفة والمنطق في العلوم الإسلامية، مرجع سابق.

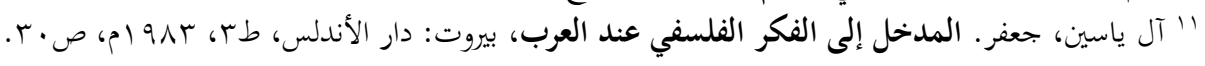

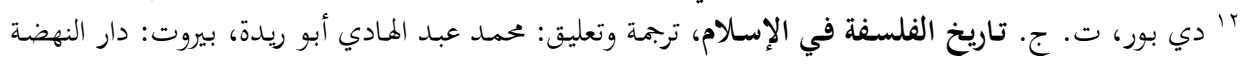

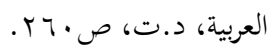

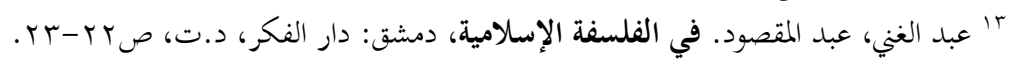




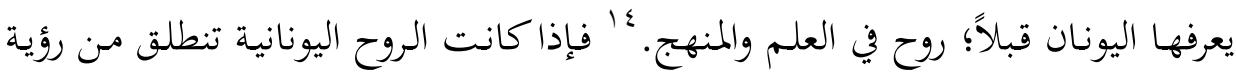

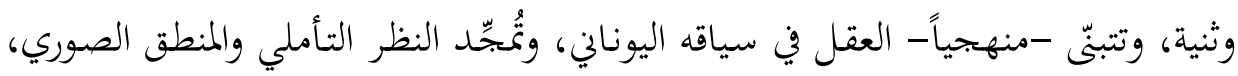

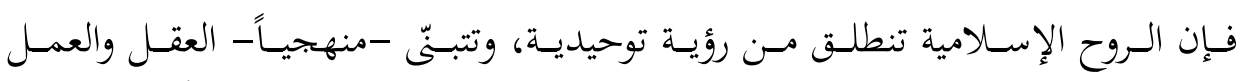

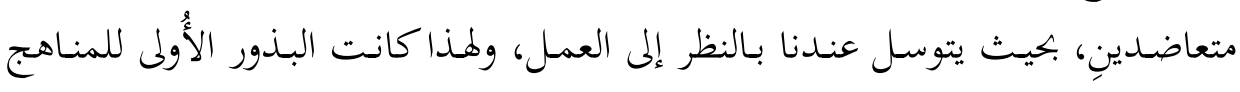
العملية التجريبية من ثمرات الروح الإسلامية.

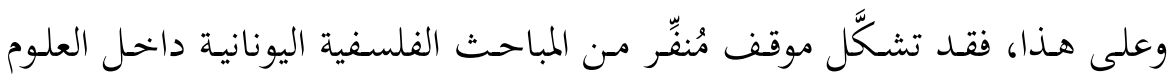

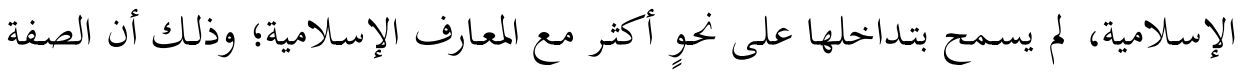

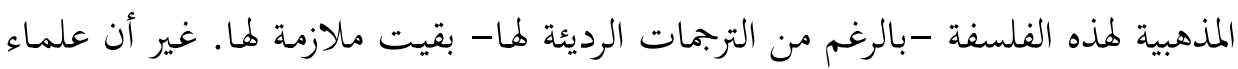

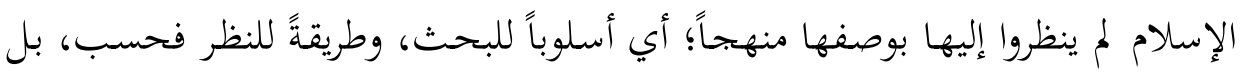

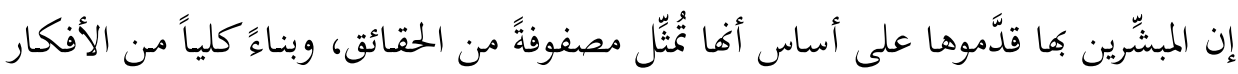

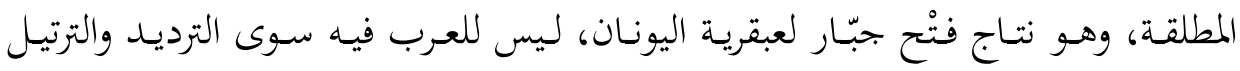
والتقليد، لا النقد والزيادة والتجديد.

وبهذا، فقد ترسَّخ تيار نقد الفلسفة اليونانية، وانتُقِد حملتها، ولا سيما من الفلاسفة

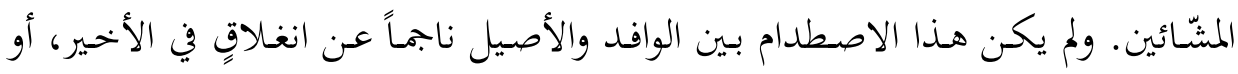

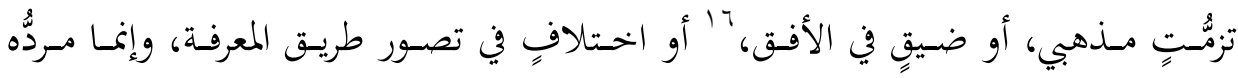

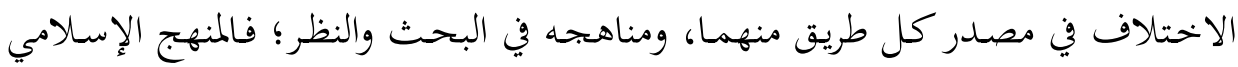

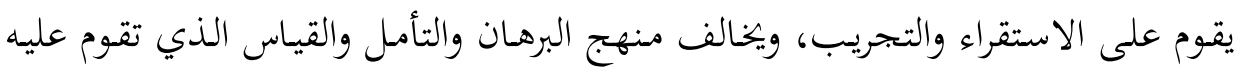

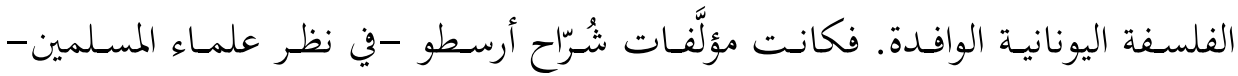

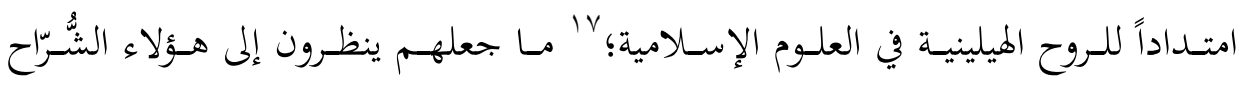

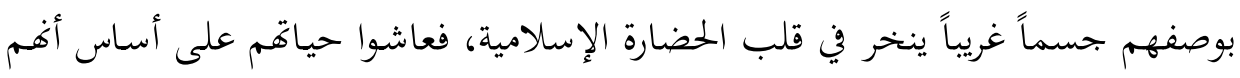
؛' النشار، مناهج البحث عند مفكري الإسلام واكتشاف المنهج العلمي في العالم الإسلامي، مرجع سابق،

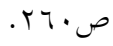
• 10 همام، أثر الفلسفة والمنطق في العلوم الإسلامية، مربع سابق.

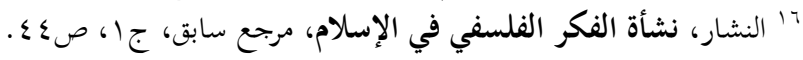
" "الشار، مناهج البحث عند مفكري الإسلام واكتشاف المنهج العلمي في العالم الإسلامي، مرجع سابق، 
متفلسفة يونـان في وسط غريـب لا يمتّون إليه بصلة، ^ا وبخاصـة أغهم لم يمتلكوا الآليـات

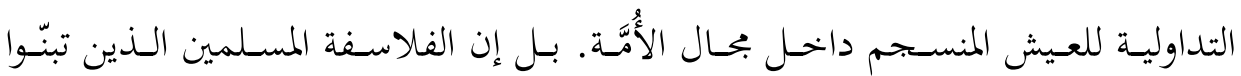

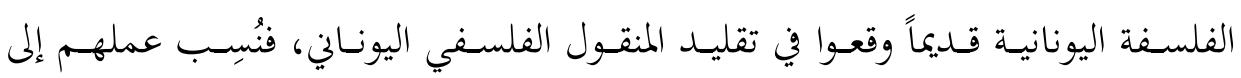
التكرار والاجترار، بل إلى السلخ والنسخ.

ولهذا السبب فشلت عمليات التداخل بين العلوم الإسلامية والفلسفة اليونانية، إلا من عمليات الإسقاط الجححفة، أو التوظيف المتعسف للمنـاهج والمفـاهيم والنظريات؛ ما أنتج فكراً هجيناً فيه من كثرة التقليد وانعدام الاتساق ما حوَّله إلى نصوص نشاز لا أصل لها ولا قرار؛ مـا قوَّى نزوع علمـاء الإسـلام إلى مقاومـة هـذا الغلو في إدخـال الفلسفة في العلوم الإسلامية.

\section{ثانياً: إغراء الفلسفة اليونانية وهامشية نقد المشّائين الإسلاميين لها}

أَسَرَ بريق الفلسفة اليونانيـة الفلاسفة المسـمين، وبلغ مـداه إلى الحـد الذي اعتقـدوا

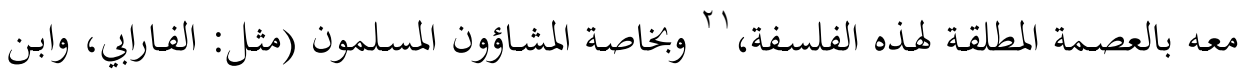
سـينا) الـذين نظـروا إلى الـتراث الفلسـفي بوصـفه نتـاج العبقـريتين الخالـدتين: العبقريـة

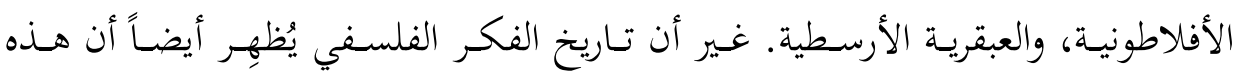
الفلسفة لم تكن خالصة النسب إلى أفلاطون وأرسطو، وإنما كانت تضم عناصر الفلسفة اليونانية الأُخرى، ونزعات صوفية غنوصية، وابجاهات دينية من يهودية إلى مسيحية، ولا سيما أن إغراء الفلسفة اليونانية قد بلغ مداه عند فلاسفة المشّيائية الإسلامية حتى اعتقدوا

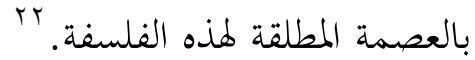

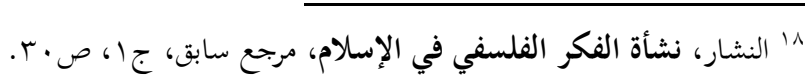

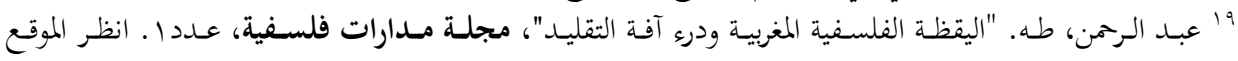

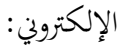

- http://philosophiemaroc.org/madarat_01/madarat01_07.htm

$$
\text { r r. همام، أثر الفلسفة والمنطق في العلوم الإسلامية، مرجع سابق. }
$$

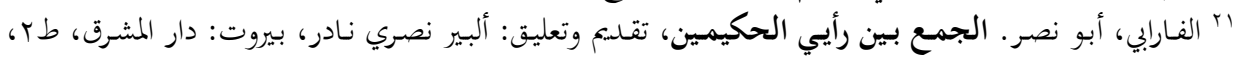

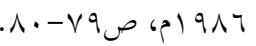

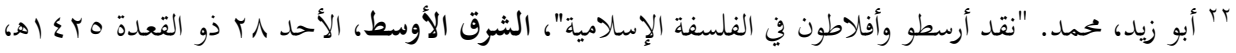


وبالرغم من استفادة الفكر الإسلامي من الفلسفة اليونانية بوصفها قوة ثقافية مؤثرة،

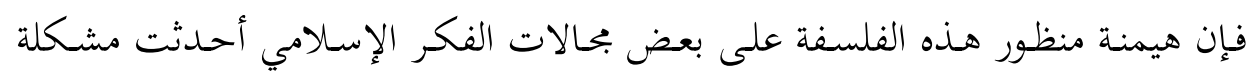

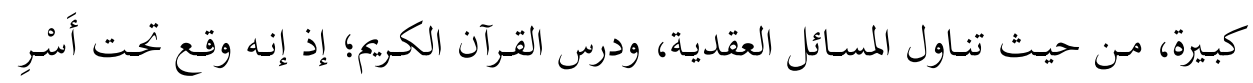
عباءة الفكر اليوناني الذي يجنح للتأمل، ولا يجتفل بالعمل. يقول إقبال: "إن الفلسفة اليونانية -على ما نعرف جميعاً-- كانت قوة ثقافية عظيمة

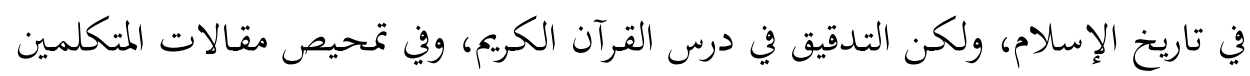

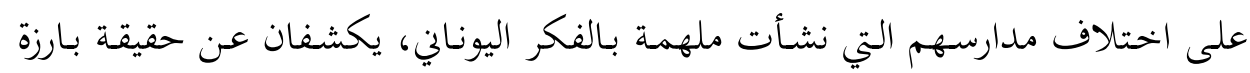

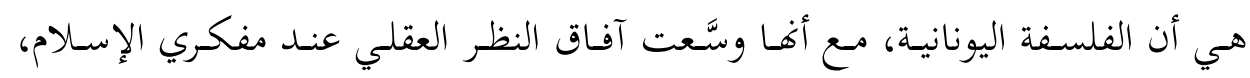

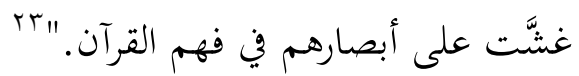

صحيح أن عبارة إقبال هـذه تبدو قاسية بتعميمها على الفكر الإسلامي واتحامه

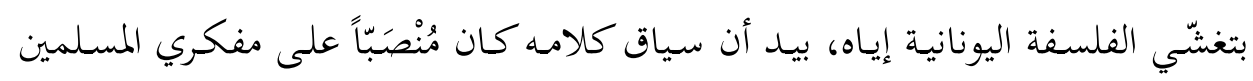

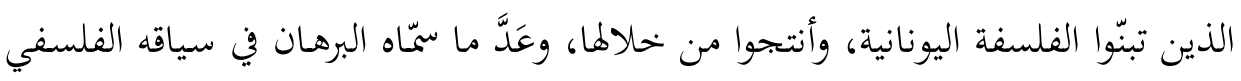

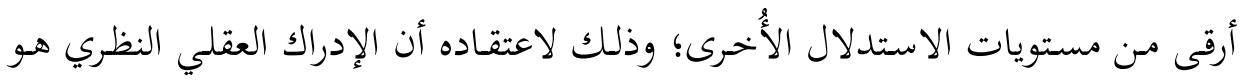

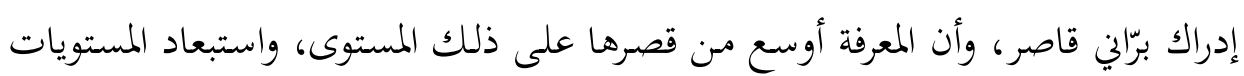
الأخرى الحسية والروحية.

ولعل موقف إقبال يفهم بوضوح من خحلال تكملة نقده الفلسفة اليونانية عُمَّلَّة في

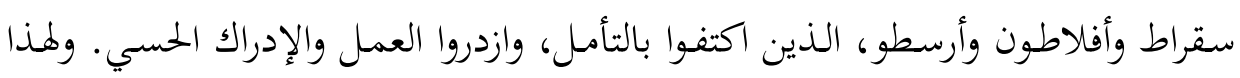

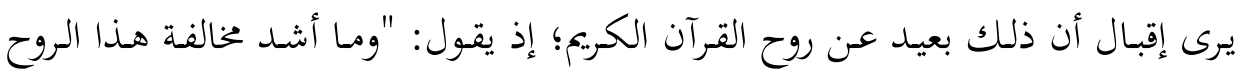

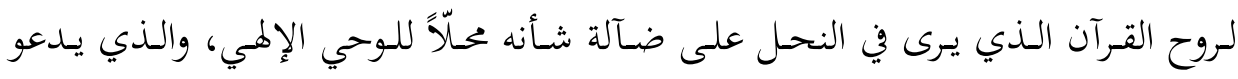

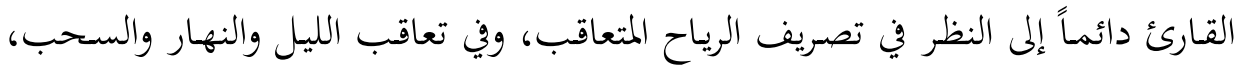

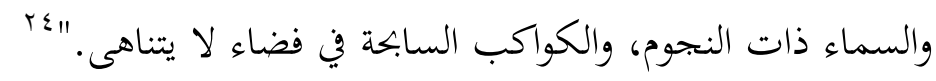

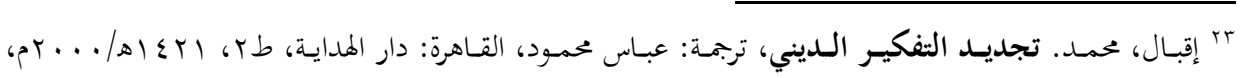
ص.1 (1)

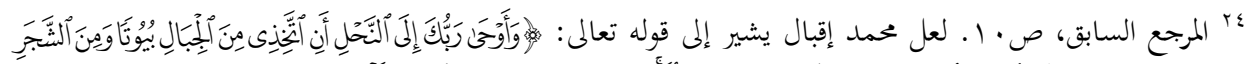

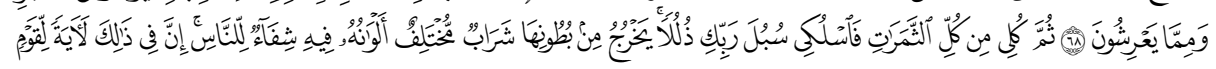




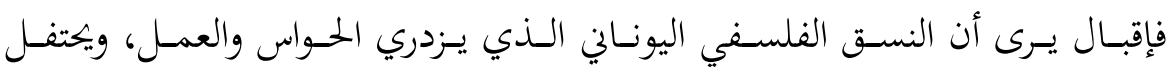

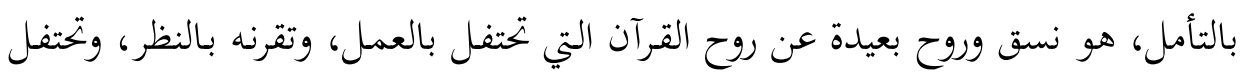

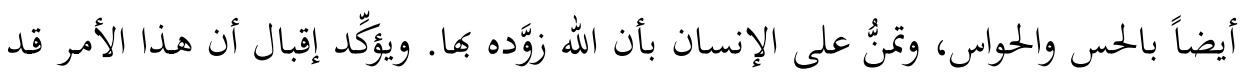

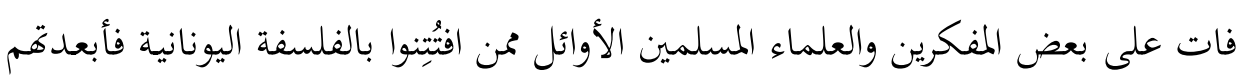
عن منطق القرآن.

وهذا ما يهبُُ إليه حسن الشافعي؛ إذ يرى أن "استناد هؤلاء الفلاسفة إلى المصادر

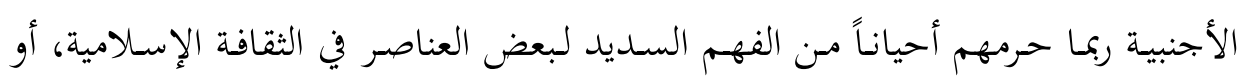

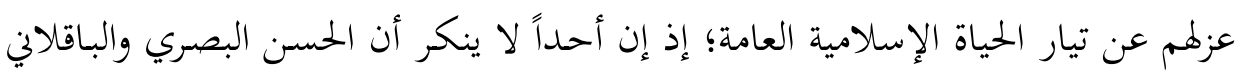

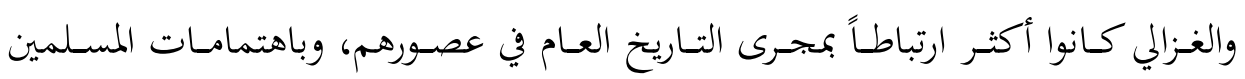

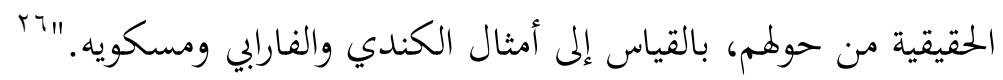

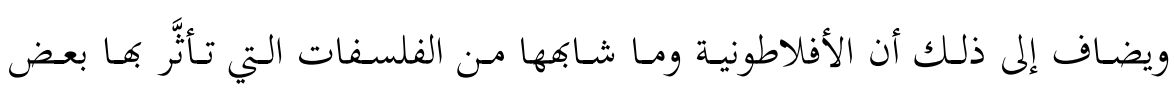

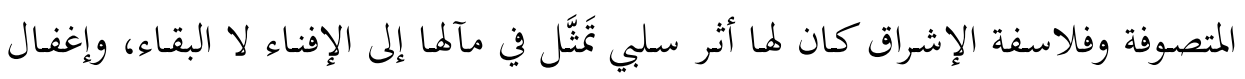

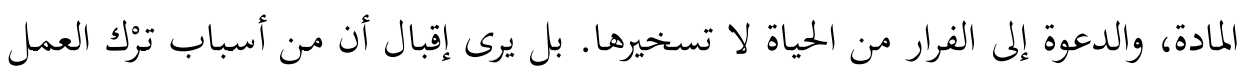

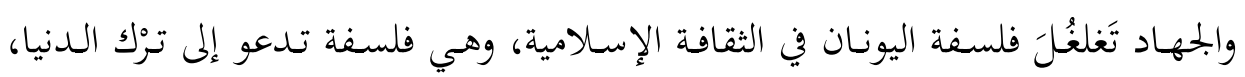
وإلى الخمول والتواكل.

لقد قضت بعض تيارات الفكر الإسلامي قرنين من الزمان لتستفيق، وتنتبه لمخالفة

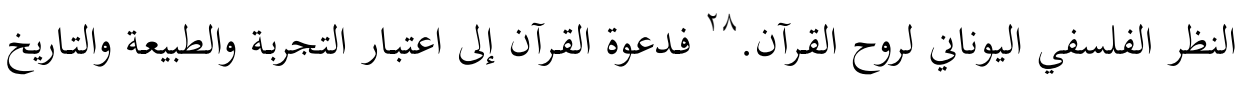

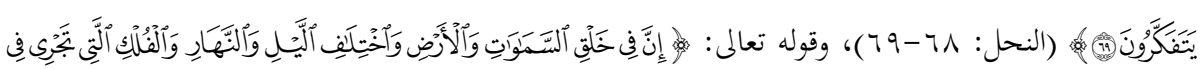

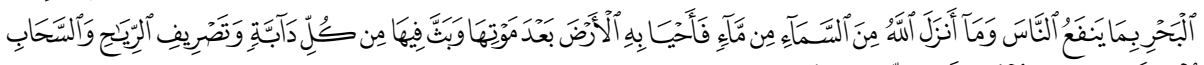

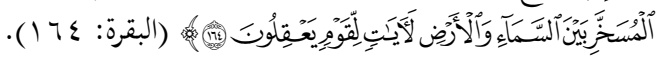
ro

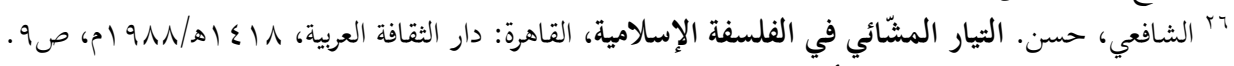

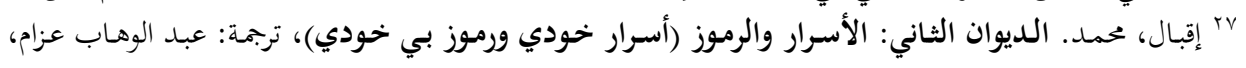

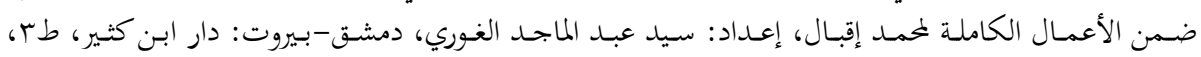
界

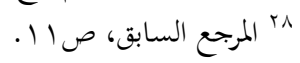


مصـادر للمعرفة، وإلى اعتبـار عـالم الحسس والاستشـهاد بـه؛ كل ذلك انتهى "بمفكري الإسلام إلى مناقضة الفكر اليوناني."

ولهذا فإن تحرُّر العقل الفلسفي الإسـامي مـن أَسْرِ العقل الفلسفي اليوناني هو مـا أدى إلى نشأة منهج الملاحظة والتجربة؛ "فإن اليونان الذين ابتهـت عنايتهم إلى النظري المحرد دون الواقع المحسوس، البحه تأثيرهم على الأكثر إلى حجب أنظار المسلمين عن فهم القرآن، ووقف حائلاً بين المزاج العربي العملي وبين إثبات وجودهه واستقلاله خحلال قرنين إني

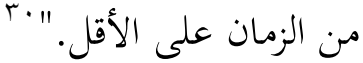

ويُعْزى سبب هذا الإخفـاق إلى أن روح القرآن تتجلّى فيها الروح الواقعية، في حين امتازت الفلسفة اليونانية بالتفكير النظري المحرد، وإغفال الواقع المحسوس، وهو مـا أدى لهى

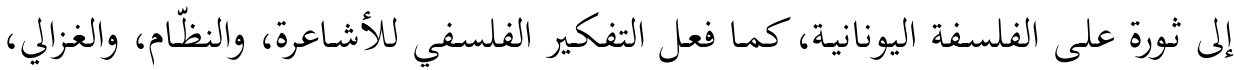

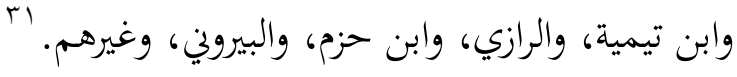

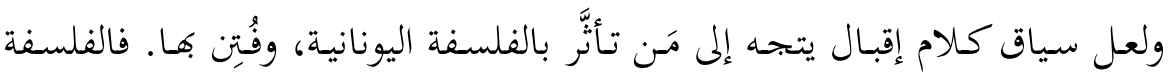

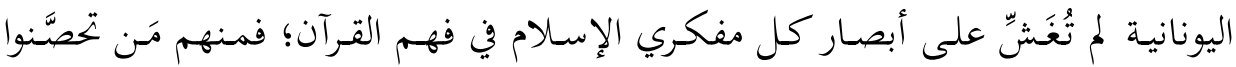

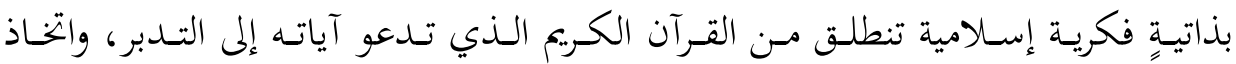
التجربـة، والتعويل على الحهواس في بنـاء المعرفة، فنفضـوا عـن أنفسهم أدران الأفلاطونيـة والصورية الأرسطية اليونانية.

غـير أن هـذا النقد الذذي توجَّهـه بـه إقبـال إلى الفلسفة اليونانيـة ومـا أحدثته بـدخولها حقل المعرفة الإسلامية، سبقه موقف كثيرٍ من معارضي الفلسفة اليونانية في تراثنا، الذي يمكن تسميته الابتحاه النقـدي في الفلسفة الإسـلامية، وهو خط فلسفي آخـر في التراث

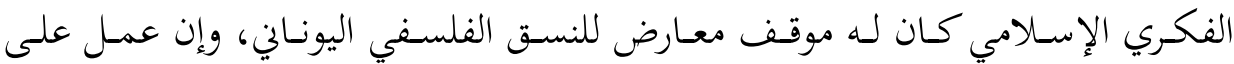
تقريب بعض مباحثه.

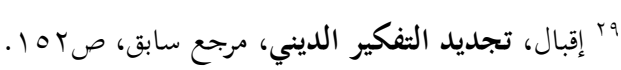

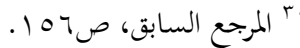

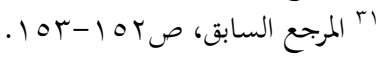


وقد بدأ هذا الخط مع المعتزلة الذين كانت لهم وقفات نقدية لا يمكن بتحاهلها إزاء

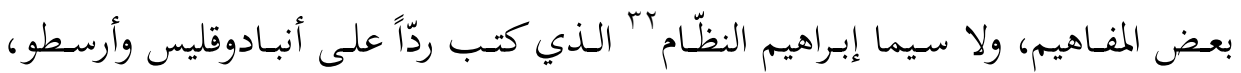

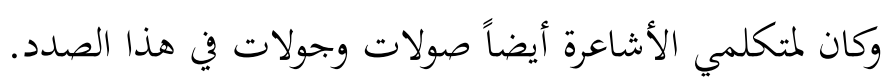

وبالرغم من القيمة النقدية لكل هذه الصولات، فإهما تتوَّجت بالحملة النقدية المنظمَّة

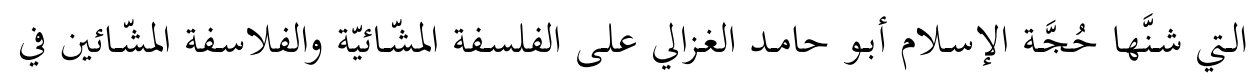

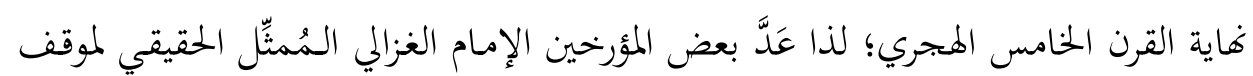

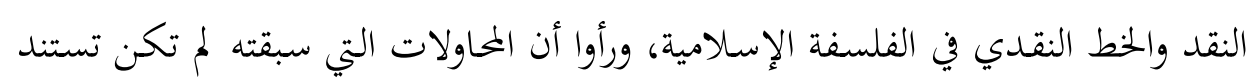
إلى أصول إبستمولوجية مؤسسة، أو لم تقم على دراسة عميقة.

ثالثاً: الاتجاه النقدي عند الغزالي I ـ التعريف بالإمام الغزالي:

يُعَدُّ حُجَّة الإسـلام أبو حامـد الغزالي أحسد أعظم أعـلام الفكر العـربي الإسـلامي،

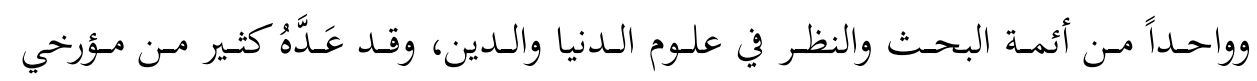

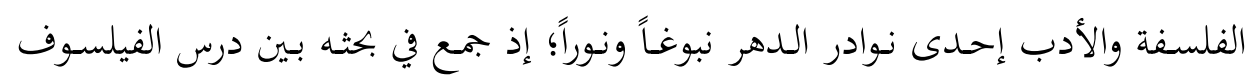

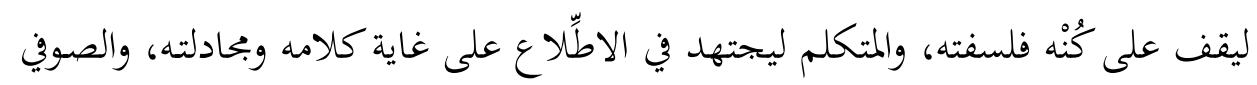

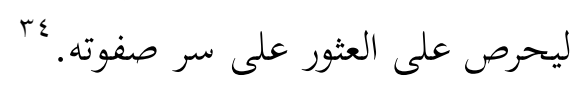

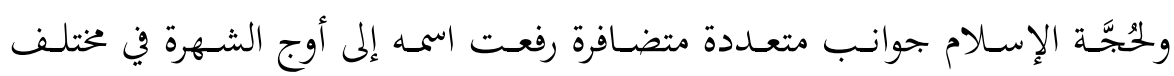

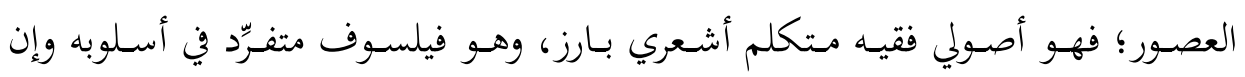
rrr أبو ريدة، محمد عبد الهادي. إبراهيم بن سيار النظّام وآراؤه الكلامية والفلسفية، القاهرة: لجنة التأليف والترجمة

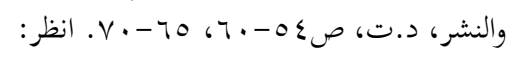
- سالم، محمد عزيز نظمي. إبراهيم بن سيار النظّام والفكر النقدي في الإسلام، النّام، الإسكندرية: مؤسسة شباب

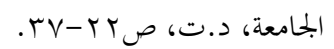

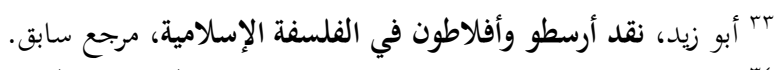

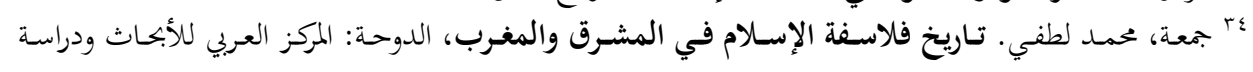

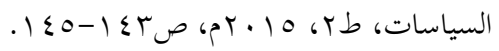


ناهض الفلسفة المشّّائيّة، وحاول تقويض بنيان الفلاسفة، وهو صوفي مُرَبِّ مُعلِّم عـالج شؤون النفس والتربية والتعليم، ومارسهما.

وكان الغزالي صـاحب عقلية متوقـدة متمـردة فكرياً على كل التيـارات الفكريـة التي

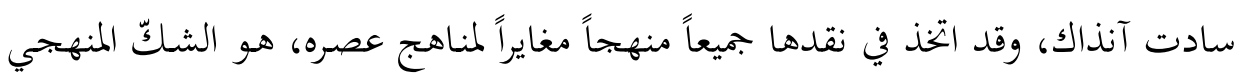
الذي يُمثّل نفس منهج أبي الفلسفة الحديثة ديكارت الذي اتخذه بعد الغزالي بأكثر من خمسة قرون.

وقد احتفى باحثون غربيون كثيرون بفكر الغزالي، ودرسوه من جوانب عدَّة، وقدَّروه

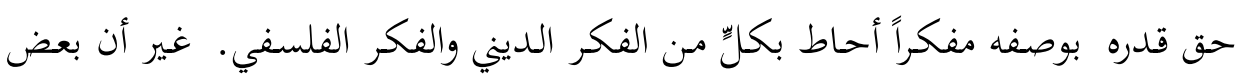
الباحثين العرب كان لهم رأي آخر؛ إذ أخرجوا الغزالي من دائرة الفلاسفة، وحمَّلوه مسؤولية

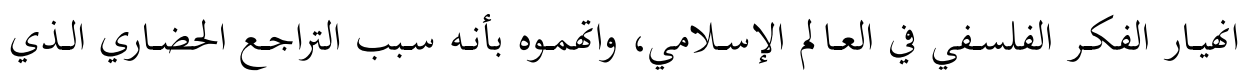

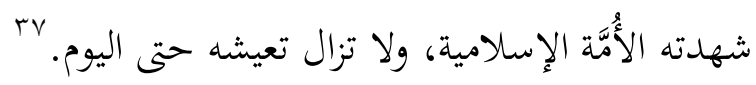

والحقيقة أن هذه نظرة سطحية اختزالية لأفكار الغزالي؛ لأن الناظر في مؤلَّفاته يجد

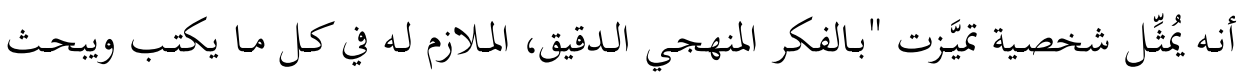

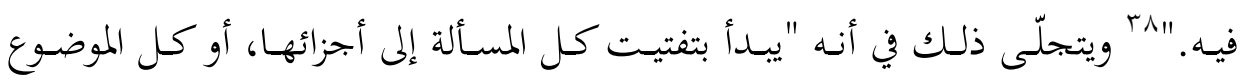

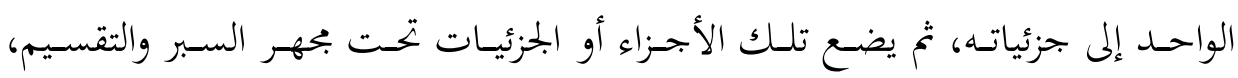

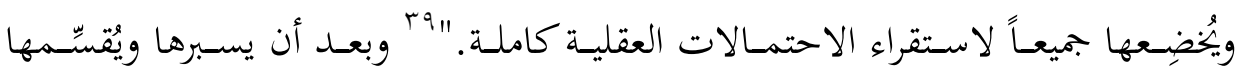

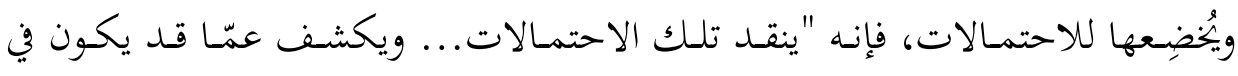

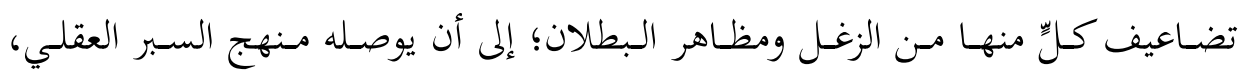

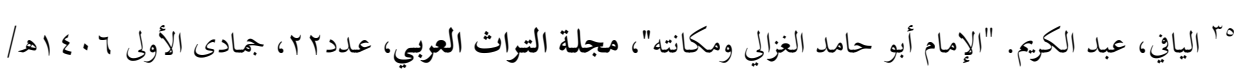

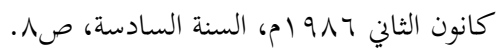

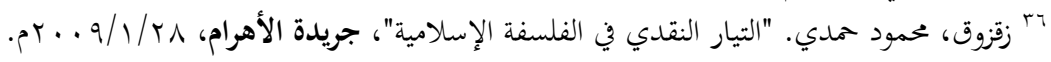

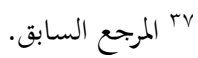

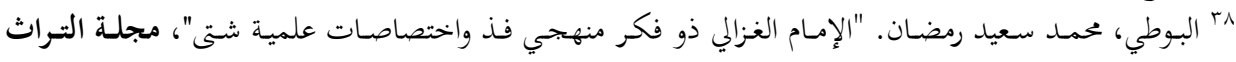

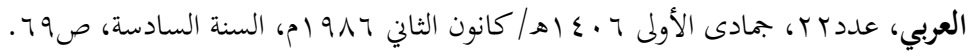


وطريقـة الطرح والإسقاط، إلى مكمـن الحـق ومنبعـه بـين تلك الفرضيات والاحتمـالات

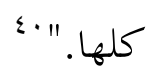

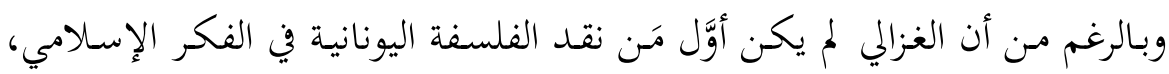

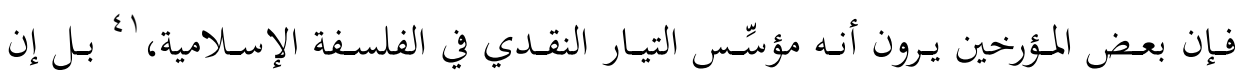

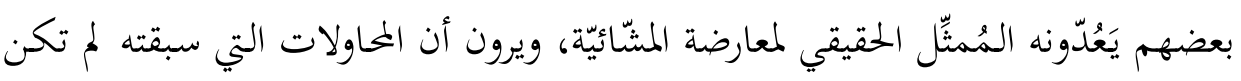

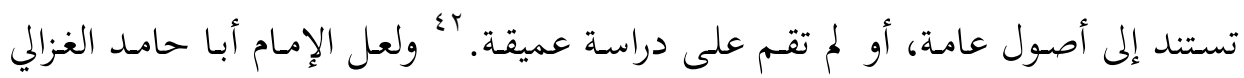

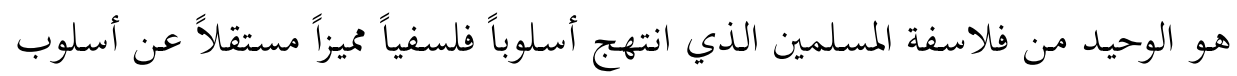

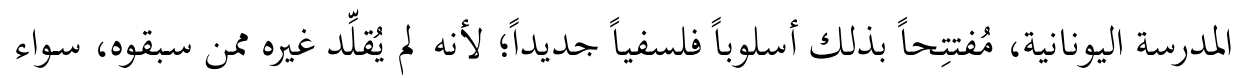

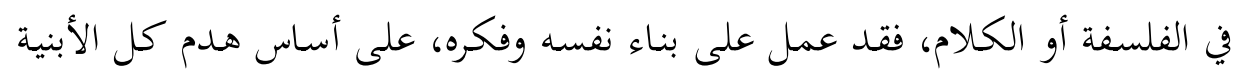

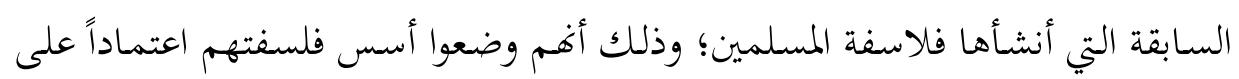

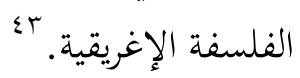

\section{Y. ب دراسة الغزالي الفلسفة سابقةٌ نقده الفلاسفة:}

في سيرته العلمية "المنقذ من الضلال" يخبرنا الغزالي قصته مع العلوم المختلفة وحقول

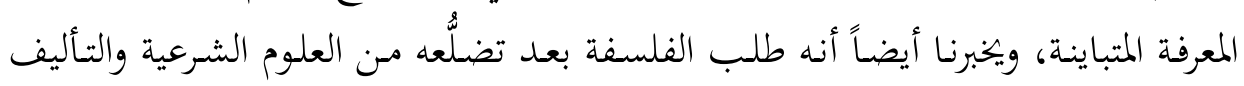

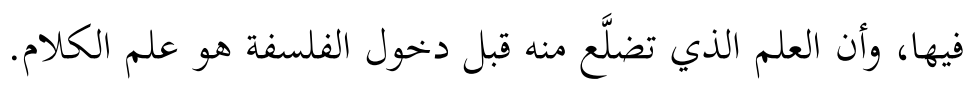
ولمّّا لم يجدـ في كتب المتكلمسين ما يساعده على الرد على الفلاسفة، فقد رأى أنه

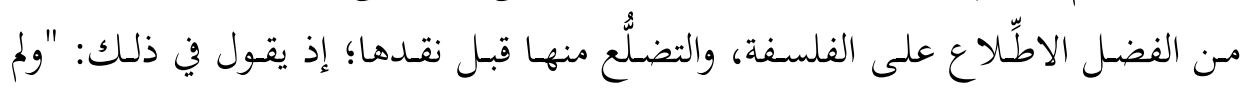

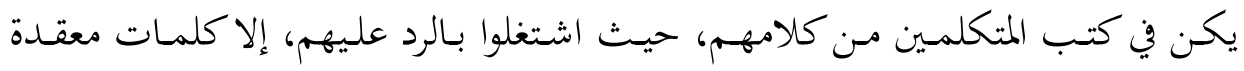

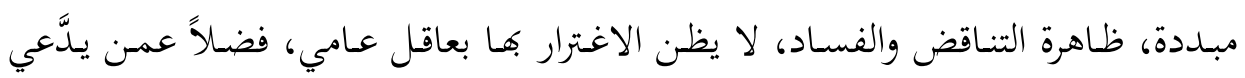

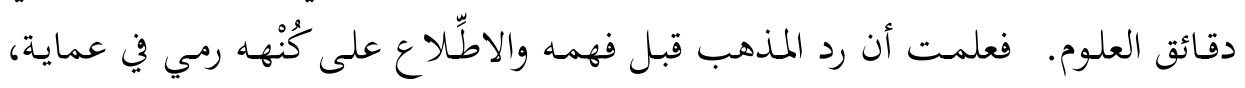

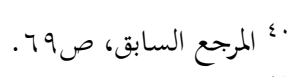

" "زقزوق، التيار النقدي في الفلسفة الإسلامية، مرجع سابق.

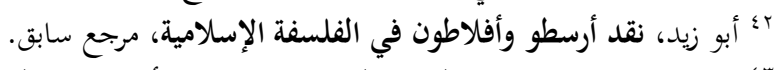

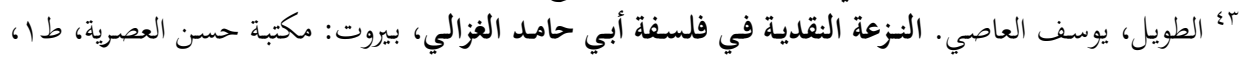

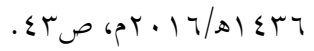




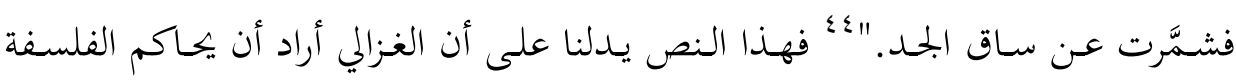

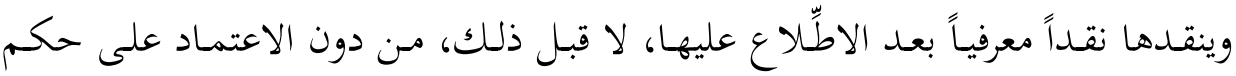
المتكلمين عليها؛ إذ لم يكن مقتنعاً بما نقله المتكلمون عنها، لأن غالب ردودهـم جدلية، فاختار الوقوف بنفسه على موضوعاتها، ومناهجها، وقضاياها، وإشكالاكها. وفي ذلـك يقــول: "تم إين ابتـدأت، بعـد الفــاغ مـن علـم الكــلام، بعلـم الفلسـفة، وعلمـت يقيناً أنه لا يقـف على فساد نوع مـن العلوم، مَن لا يقف على منتهى ذلك العلم، حتى يساوي أعلمهمم في أصل ذلك العلىم، ثم يزيد عليه، وبيجاوز درجتـه، فيطلَّع على ما لم يطلَّع عليه صاحب العلم من غور وغائلة، وإذا ذاك يمكن أن يكون ما يدَّعيه من فساده حقّاً. " من

وهـذا السـعي للوقـوف على منتهـى الفلسـفة وغايتهـا تطلَّبَ مسن الغـزالي المطالعـة والمدارسة لكتبب الفلاسفة، ثم المراجعة وتقليـب النظر فيها. وقد بـذل جهده في مطالعة هذه الكتبب ومدارستها خحلال أوقات فراغه مـن الكتابة والتدريس في العلوم الشرعية، في أقل من سنتين، حتى وقف على منتهى علومهم، بَ؛ وهو في ذلك مواظب على تقليـب الرأي فيهـا، أو كمـا يقـول: "ثم لم أزل أواظـب على التفكـر فيـه بعـد فهمـهـ... أعـاوده، وأردده، وأتفقـد غوائلهه وأغـواره، حستى اطلَّعـت على مـا فيـه مـن خـداع وتلبيس، وتحقيـق

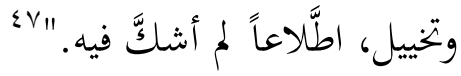

وقد انتهى بـه ذلك إلى أن في الفلسفة مـن حيـث مضـامينها "مـا يُنَّم منها، ومـا لا

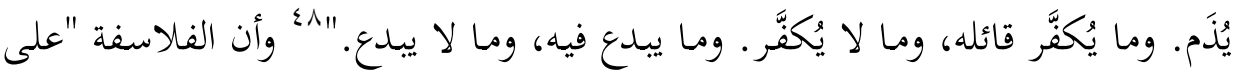
كثرة فرقهم واختلاف مذاهبهم... ثلاثة أقسام: الدهريون، والطبيعيون، والإلهيون. "9؛ ئ ؛؛ الغزالي، أبو حامد. المنقذ من الضلال، تحقيق: سعد كريم الفقي، الإسكندرية: دار ابن خلدون، د.ت، صها 1 .

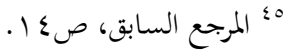

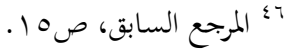

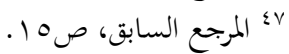
هـ محمود، عبد الحليم. المنقذ من الضلال مع أبحاث أخرى في التصوف ودراسات عن الغزالي، القاهرة: مطبعة 
تم عمل على تصـنيف هـذه الأقسـام، وعرضـها، وتحليلهـا؛ فاللـهريون هـم الـذين

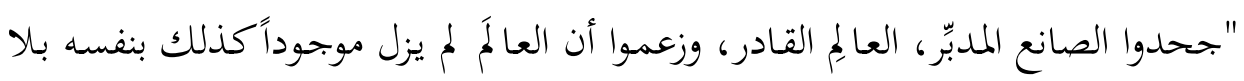

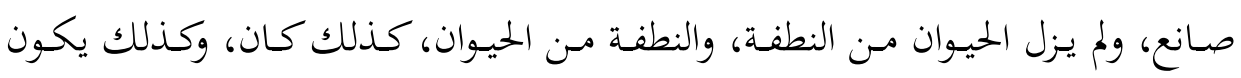

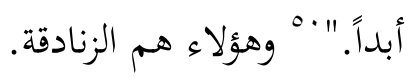

أمّا الطبيعيـون فهـم بـالرغم مـن "الاعـتراف بفـاطر حكيم.... إلا أن هـؤلاء، لكثـرة

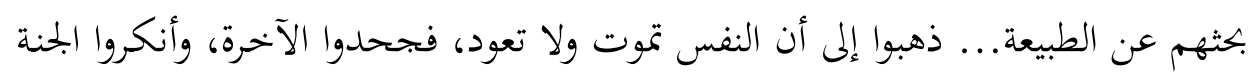
والنار، والحشر والنشر، والقيامة والحساب، فلم يبقَ عندهم للطاعة ثواب، ولا للمعصية

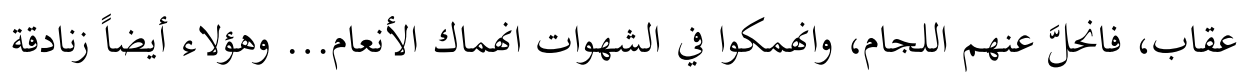

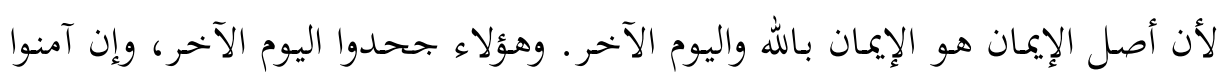

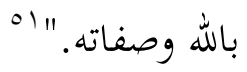

وأمّا الإلهيون فيُمَتّلهم سقراط، وأفلاطون، وأرسطاطاليس، "وهـم بجملتهم ردوا على

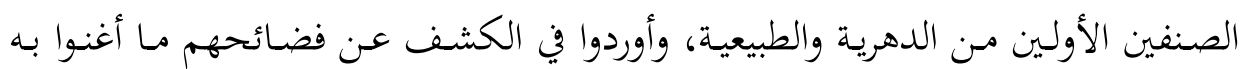

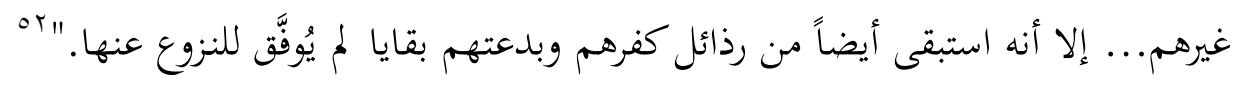
ثم إن الغزالي استخلص عشرين مسـألة مُّا ينبغي نقـد الفلاسفة فيها، واستخلص ثلاثاً من تلك المسائل العشرين عَدَّها موجبة للكفر، هي: القول بقِدَم العالمَ، والقول بأن

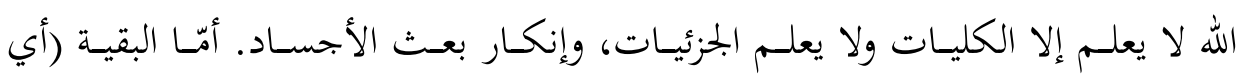

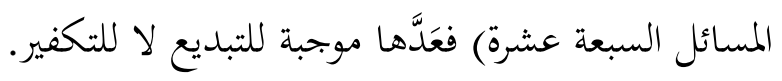

والنـاظر في هـذه المسـائل وتعامُل الغزالي معها، يـرى أنه أحصى المباحـث والقضـايا

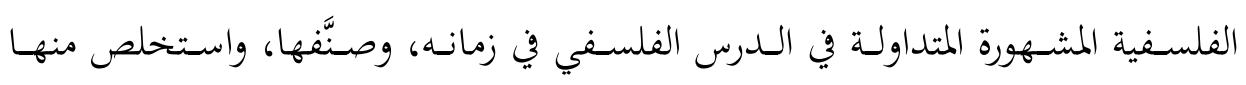

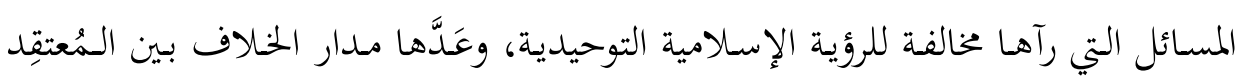
بالإسلام، والمُتبني للميتافيزيقا المشيّائيّة اليونانية.

$$
\text { 10 المرجع السابق، صع ا. المرجع السابق، صه ا. المرجع السابق، صه } 1 .
$$


والحقيقـة أن الغزالي في تقسيمه أصسناف الفلسفة، وأقسـام الفلاسفة، قـد أبـان عـن مقدرة منهجية تحليلية، وحس نقدي جريء، في مقاربته للفكر الفلسفي اليوناني كما تَثََّّه

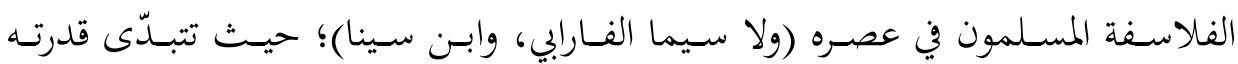
التحليلية في تصنيف الفلاسفة.

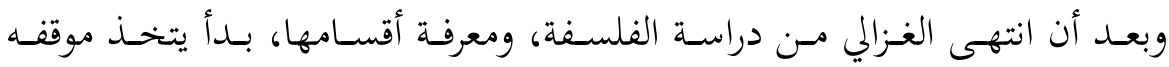

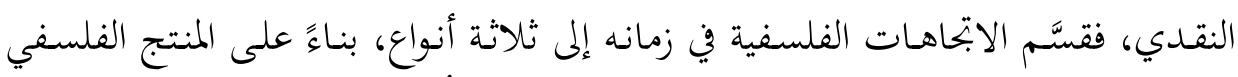

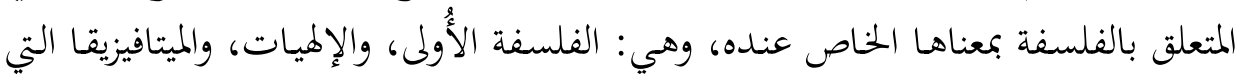
تتضمَّن البحث في الغيب والوجوديات.

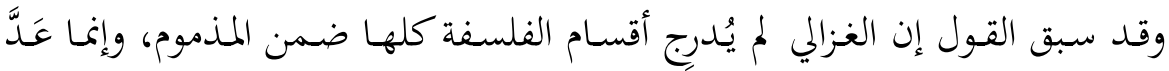

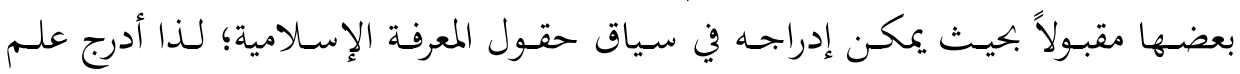
المنطق في "المستصفى "به ضمن العلوم المقبولة في حقل المعرفة الإسـلامية، وعَدَّه معياراً

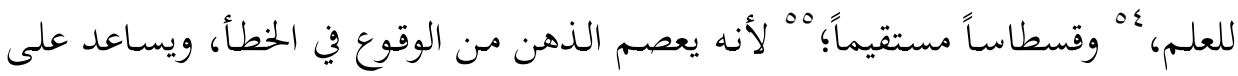

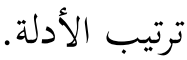

ورأى الغزالي أن ابن سينا والفـارابي هما أفضل مَن نقل فلسفة أرسطو المشّّائيّة؛ لذا

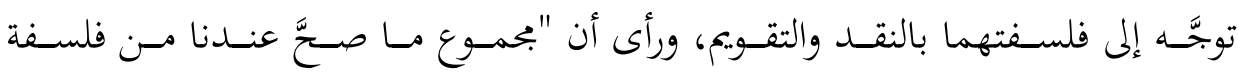
أرسطاطاليس، بحسب نقل هذين الرجلين، ينحصر في ثلاثة أقسام: قسم يجبـ التكفير

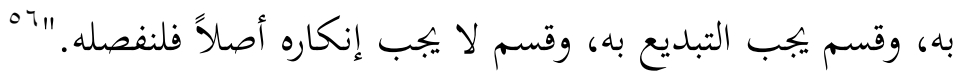

وعلى هـذا، فقـد توجَّه الغزالي بالنقـد إلى المدرسة الفلسفية السـائدة في زمانه، وهي

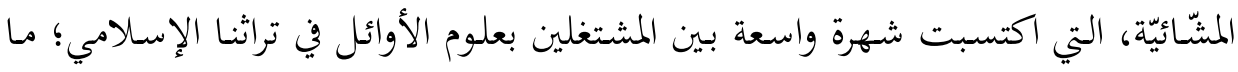

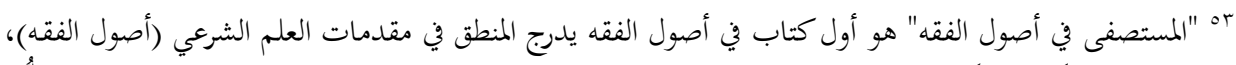

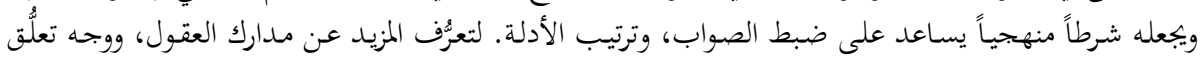

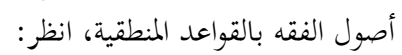

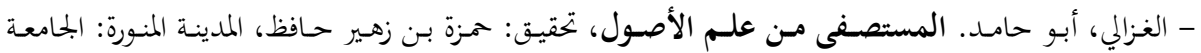

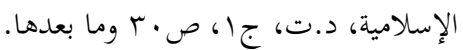

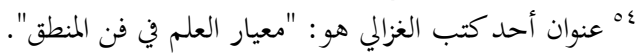

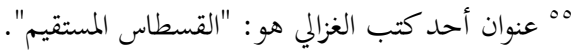

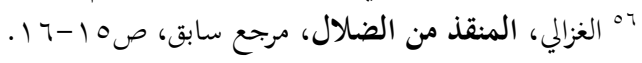


جعله يخصـها بنقـده، ولا سـيما أن أهلهـا أوصـلوها -وهـي اشـتغال عقلهي - إلى درجـة التقديس، ورفعوها إلى مستوى النص المقدس.

ولكن ما يظهر من اشتغال الغزالي بمناقشة الفلاسفة ورد فلسفتهم الإلهية في نسختها المشّائيّة، هو الابتداء ببسط الكالام في مذاهبهم وقضاياهم وعرضها قبل نقدها، وقد بلغ من حرصه على هذا المنهج أن ألَّف كتاباً في مقاصد الفلاسفة حين هَمَّ بتأليف كتاب في تَافتهم؛ إذ يقول: "ولنفهم الآن ما نورده على سبيل الحلكاية مهمالً مرسالً من غير بحثث عن الصحيح والفاسد، حتى إذا فرغنا منه استأنفنا له جداً وتشميراً في كتاب مفرد نُسمّيه قهافت الفالسفة.

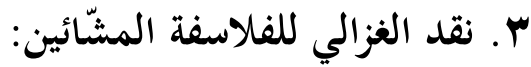

يُعَدُّ أبو حامد الغزالي في طليعة مفكري المسلمين الذين اتخذوا موقفاً ناقداً للفلسفة اليونانيـة في نسـتهـا المشّــائية خاصسةً، وفي معناهـا الخـاص (الإلهيـات)، ويظهر ذلك في بعض مؤلَّفاته، مثل "مقاصد الفلاسفة" الذي تتبَّع فيه مسار الفلسفة المشّائيّة في البحال الإسالامي بعرضٍ دقيق لموضوعاةًا، ورموزها، وقضاياها، وإشكالاتها، بصورة موضوعية، وحيـاد فلسفي قصـد منـه الغزالي أن يجعله مقدمـة ضـرورية للـرد على الفلاسفة في كتابـه

$$
\text { الآخر "قهافت الفلاسفة". }
$$

ومن مراجعة "المنقذ من الضهلل "، و "مقاصد الفلاسفة"، و "قافت الفلاسفة"، بهد أن الغزالي درس الفلسـفة في نيسـابور وبغـاد، وبـرع فيهـا، وأحساط بإشـكالاتما، وصسنَف فيها، ورد على آراء الفلاسـفة. ولكـن رده على آراء الفلاسـفة التي رآهـا متعارضسة مـع العقيدة الإسلامية صراحةً، جعل بعض الباحثين يرون أنه قضى على الفلسفة، في حين رأى بعضهم أنه فيلسوف بمعناه الصحيح، كما هو واضح من دراسته الفلسفية والمنهجية في البحث عن الحقيقة، ونقده آراء الفلاسفة بمنهج فلسفي. ^ه

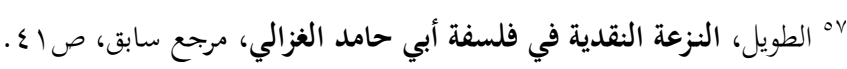

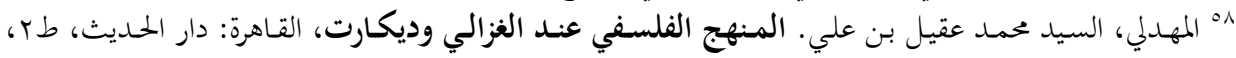


فهذه المؤلَّفات التي شنَّ من خلالها الغزالي حملات نقدية على الفلسفة والفلاسفة

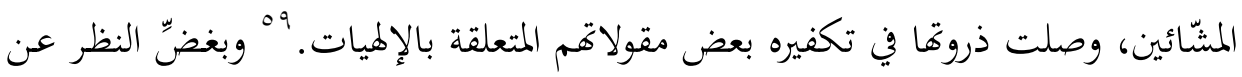
هذا الحكم العقدي الذي يتضمَّن رفض الغزالي مضامين القضايا المخالفة للثابت الإيماني المبرهن نقـلاً وعقلاً، فإنه لم ينتقد الفلسفة، أو يعترض عليها - كما سيتبين - في ذاتها،

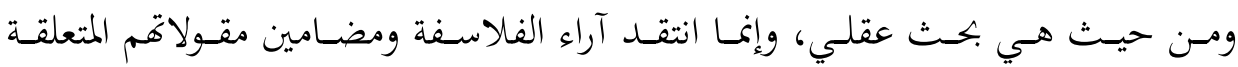

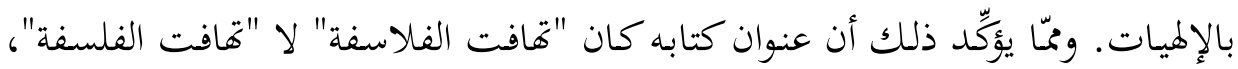
لكن الفهم الخطأ جـاء مـ التلازم بين الفلسفة والفلاسفة، كما في التلازم بين الإسلام

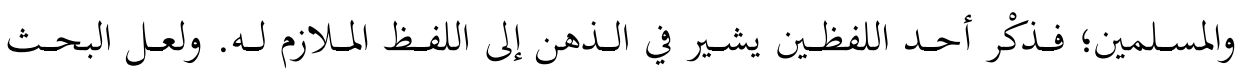

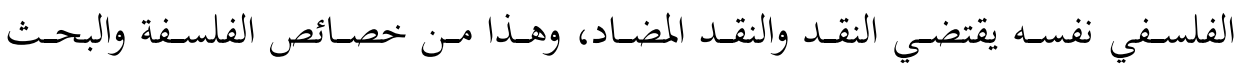
الفلسفي، والغزالي قد فعل ذلك. وفي المقابل، فهو لا يقتضي ما أشـاعه خصوم الفكر الإسلامي من المستشرقين وأتباعهم من أن الغزالي بنقده هذا قضى على البحث الفلسفي كما أسلفنا.

وهذا ما سنتبينه أكثر بتحليلنا النقد التفصيلي الذي قدَّمه الغزالي للفلاسفة ومباحث الإلهيات، وبخاصة الفلسفة المشّائيّة؛ إذ سيتضح لنا مـن عناصر النقد المعايير التي اتَّعها الغزالي في نقده المشّّائيّة.

\section{أ. نقد الانبهار وعقدة النقص والتقليد للمشّائيّة:}

إن أول معيـار انطلـق منـه الغـزالي في نقــده للمشّّائيّة هـو كسـره الانبهـار النفسي،

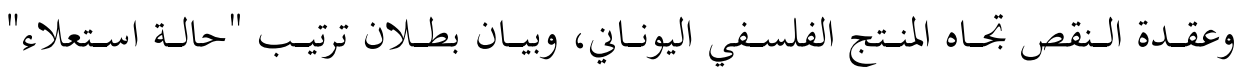

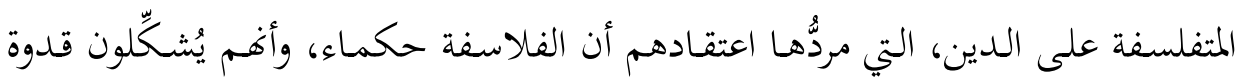
مثلى في كل جانب.

ففي سياق الحلديث عن سبب تأليفه كتاب "تافت الفلاسفة"، يؤِّد الغزالي وقوع هؤلاء تحت تأثير الفلسفة اليونانية في صورة انبهار بليد، واستعلاء أجوف على على الشعائر 
والوظائف الدينية، من دون الاستناد إلى أساس برهاني، والاكتفاء بالتقليد والوقوع في أَسْرِ النص الفلسفي المشائي من دون تمحيص.

إن الاسـتعلاء الأجـوف على الالتـزام بشـعائر الإسـلام بـدعوى التميُّز، وأن الـدين

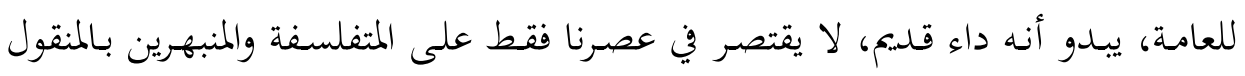

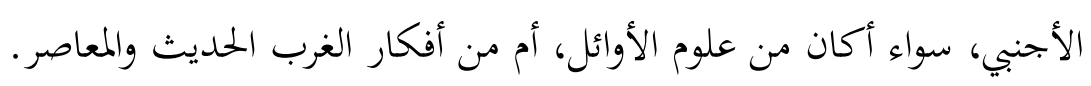
وقد سجَّل الغزالي هذه الملحوظة على المتفلسفة المشّّائين في زمانه؛ إذ قال: "أمّا بعدُ فإين رأيت طائفة يعتقدون في أنفسهم التميُّز عن الأتراب والنظراء، بمزيد الفطنة والذكاء،

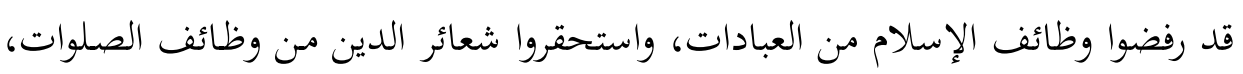

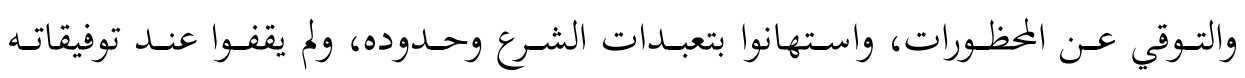

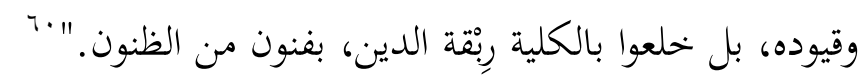

بيد أن هذا الاستعلاء على الشعائر الدينيـة والولاء للدين تقابله استكانة، وتقليد

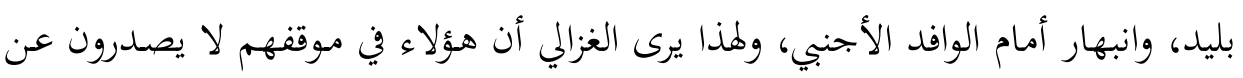

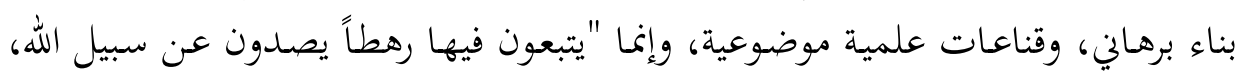

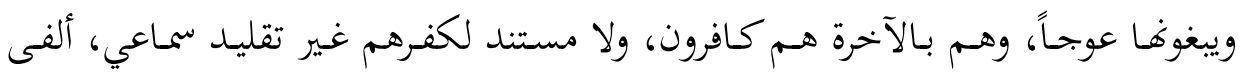

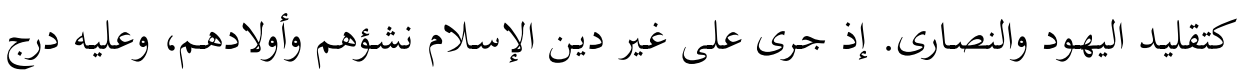

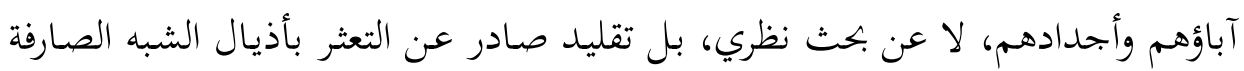

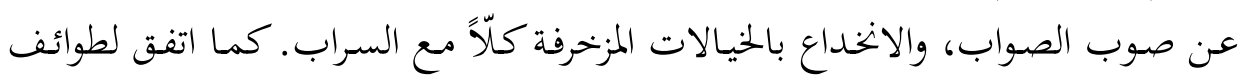

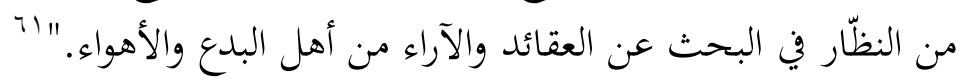

والمتأمل في النص يجد أن الغزالي يشير إلى دور التنشئة الاجتماعية في تربية الإنسان على مواقف يحسبها عقلية برهانية، وهي في جوهرها تقليد أجوف لا روح فيه. ولعل هذا لـا

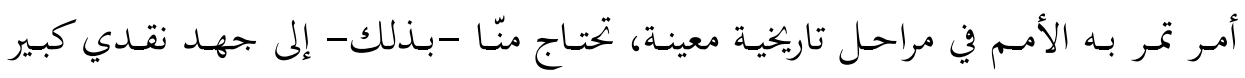

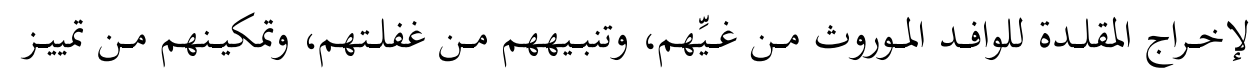
البرهاني من التلقيني.

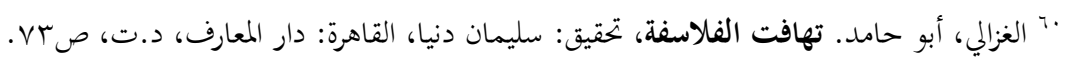

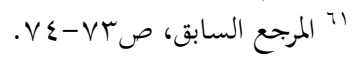




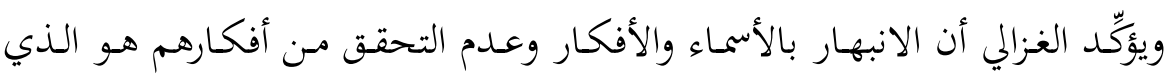

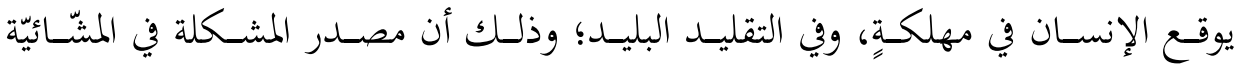

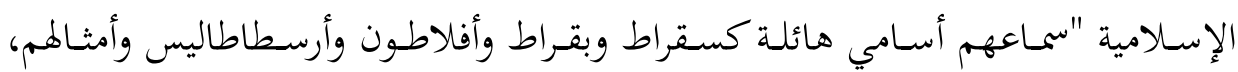
وإطناب طوائف من متبعيهم وضلالفم في وصف عقولهم، وحسن أصولهم، ودقة علومهم

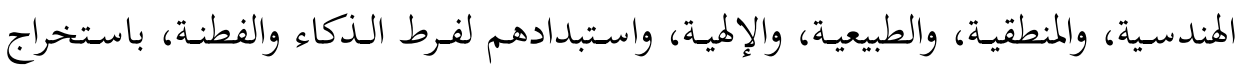

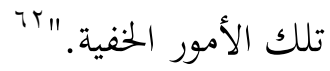

ولا شـكّ في أن هـذا التصـوير الانبهـاري لعلوم الأوائـل، وفلاسـفة اليونـان خاصـةً، وأفلاطون وأرسطو على نحِِ أخص، جعل الناس تنبهر بهم، وتأخذ عنهم كل شيء من ولن

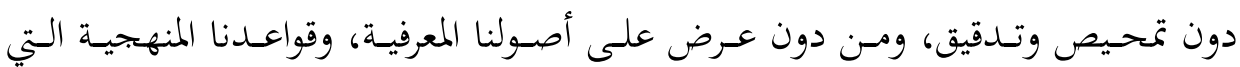
أرساها الإسلام.

والحقيقـة أن هـذا الانبهار يُمثِّل عائقاً نفسياً أمـام النقـد، ودافعـاً إلى الوقوع في أَسْرِ

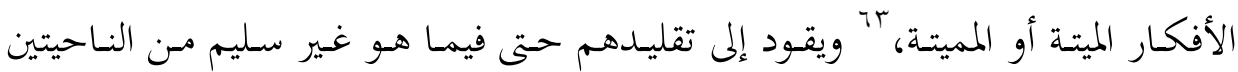

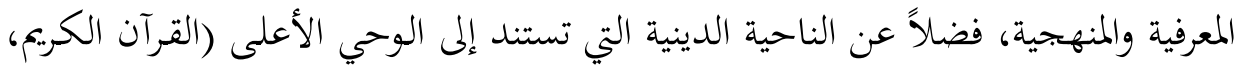

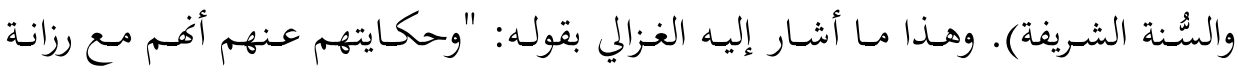

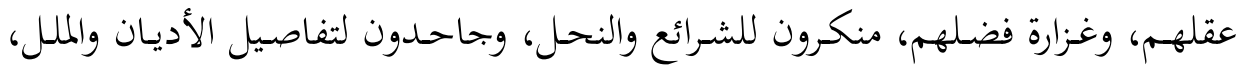

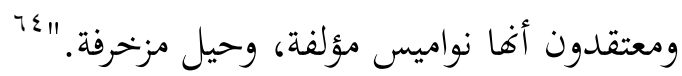

وهـذا التقليد الموسوم بمغالطات العقلانيـة وإعمـال العقـل، الذي أشـار إليه الغزالي،

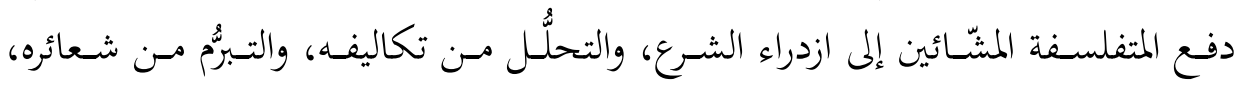

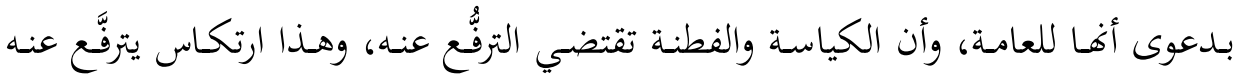

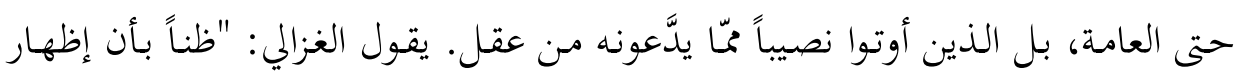

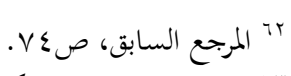

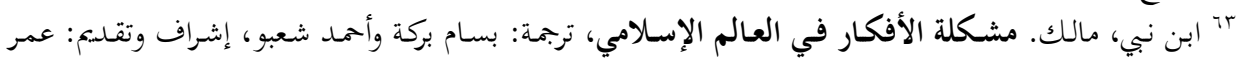

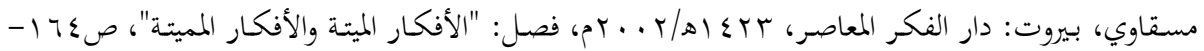


التكايس في النزوع عن تقليد الحق بالشروع في تقليد الباطل جمال وغفلة منهم، عن أن

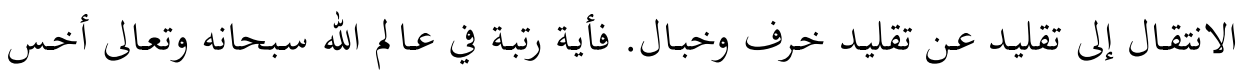

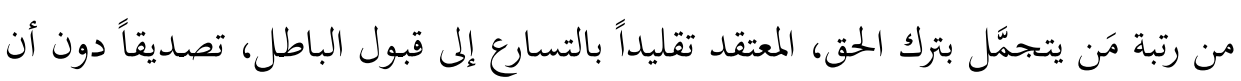
يقبله خبراً وتحقيقاً.

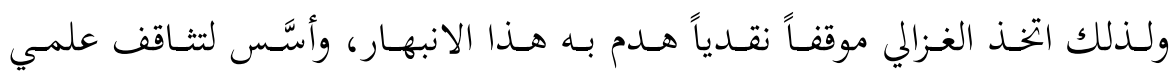

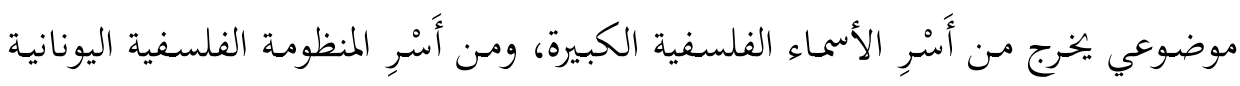
المنقولة.

\section{ب. تخصيص الإلهيات والطبيعيات المثّائيّة بالنقد:}

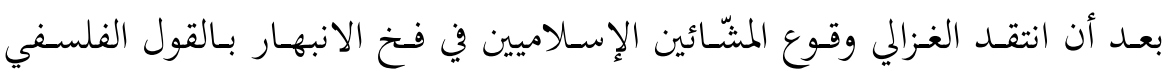

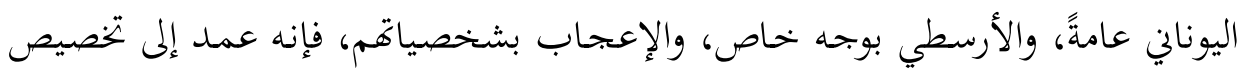

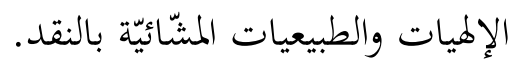

وفيما يخص الأقسـام الثلاثة التي أصدر الغزالي حكمـه فيها - كمـا أسـلفنا- فبإن

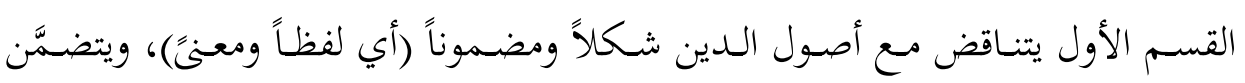
ثلاث قضايا هي: القول بقِدَم العالم، وإنكار بعث الأجساد، وإنكار علم الله بالجزئيات. وموقف الغزالي منه التكفير؛ وذلك أنه قسم يخرج بصاحبه من التصور الذي أسَّس له له

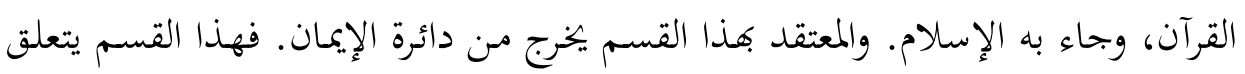

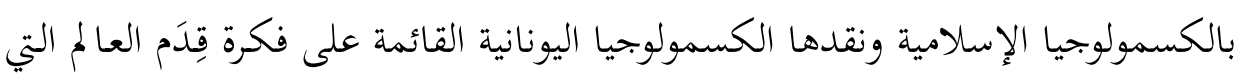
تقـوم على فكـرة الضـرورة، وتقتضـي نفي نظريـة الخلـق، ويتبعهـا القـول بعـدم علـم الله

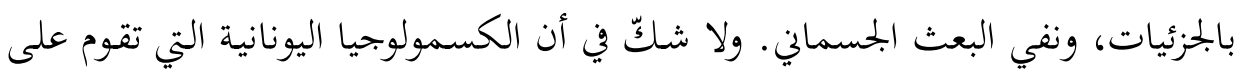

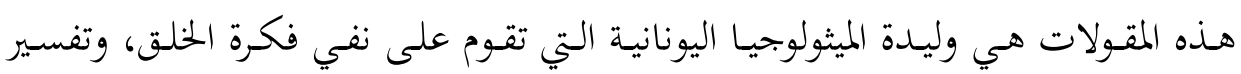
الوجود عن طريق نظرية الفيض، التي تحمل في طياتها صعوبات لا تنتهي. فالغزالي كأنه

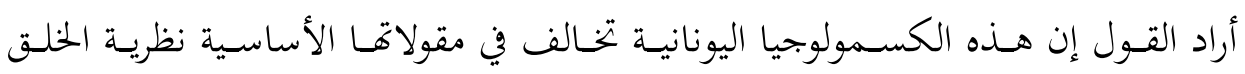


الإسلامية القائمة على فكرة الإرادة الإلهية، والحلق، وإغـا تختلف في كلياتا وجزئياتا عن هذه الميثولوجيا اليونانية.

أمّا القسم الثاني فهو الذي يتناقض مع هذه الأصول شكلاً (أي لفظاً)، ويتضمَّن سبع عشرة قضية. وموقف الغزالي منه التبديع؛ أي إن القائل بمقولات هذا القسم أصابه

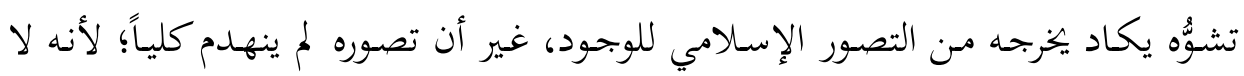
يخالف الأصول وإن خالف الشكل.

ولهذا اشتغل الغزالي بنقض مقولات الإلهيات المشّّائيّة "ردّاً على الفلاسفة القدماء،

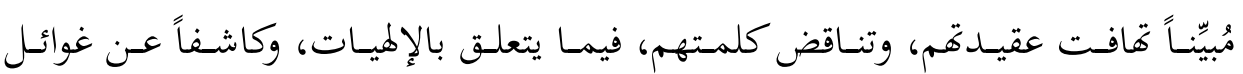
مذهبهم، وعوراته التي هي على التحقيق مضاحك العقلاء، وعبرة عند الأذكياء. أعني:

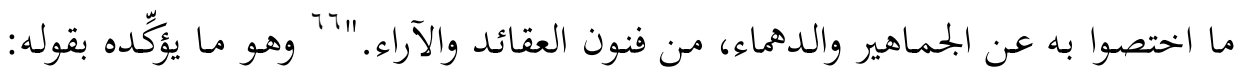
"نحن لم نخض في هذا الكتاب خوض الممهدين، بل خوض الهادمين المعترضين، ولذلك

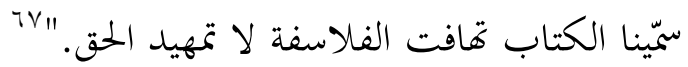

وهو بـذلك يهـدف إلى إظهار الفاقـة المعرفيـة لخطاب المتفلسفة الإسـلاميين الـذين يتَّعون أرسطو؛ إذ سعى الغزالي إلى إظهار عجزهم عن البرهان على دعاواهم، وأها بحرد إطها

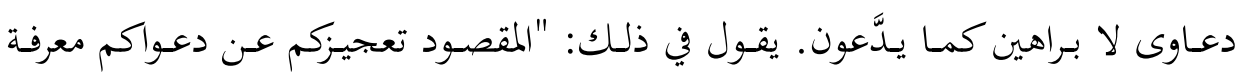

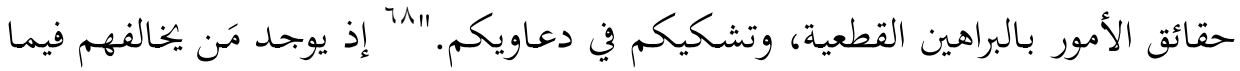
يذهبون إليه، ويُبطِل دعاواهم البرهانية، ولا سيما مـا يتعلق بـالأمور الغيبية الشرعية التي تُبْنى على مصدرية الوحي لا على تخيلات العقل، وما العقل فيها إلا متبع؛ لأهنا تتجاوز

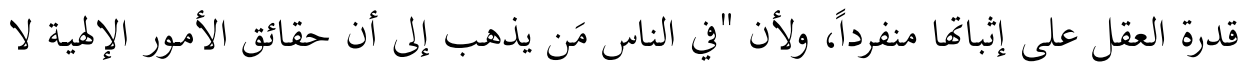
تُنال بنظر العقل، بل ليس في قوة البشر الاطّّلاع عليها."

$$
\begin{aligned}
& \text { YT المرجع السابق، صه V. }
\end{aligned}
$$

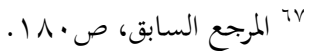

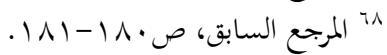

$$
\begin{aligned}
& 979
\end{aligned}
$$


فــدوى برهانيـة الإلهيـات المشّــائيّة شـيء لا يقبلـه عقـل؛ لأن الفلاسـفة أنفسـهم ختتلفـون ومتنـازعون فيـه، وأسـاليبهم متبـاعـدة عن بعضهـا بعضـاً. يقول الغزالي: "ليعلم أن الخوض في حكاية اختلاف الفلاسفة تطويل، فإن خطبهم طويل، ونزاعهم كثير، وآراؤهم منتشرة، وطرقهم متباعدة متدابرة.

ولم يكتـفِ الغزالي بهـا النقـد الذي وجَّهـهـ إلى الفلاسفة؛ فقـد نعـت الآراء والأفكار التي تركها فلاسفة اليونان والإسهام بأفها مليئة بالتخبيط، والتخليط، والتشويش، 'V ورأى أن مذاهب الفلاسفة لا يقـين فيها ولا ثبات؛ فهـم يعتمدون فيها على الظن الذي تقوم عليه براهينهم في الإلميات، مـا جعلهم يختتلفون بخصوصها. وفي ذلك يقول الغزالي: "لا

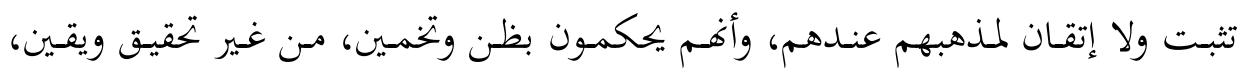
ويستدلون على صدق علومهم الإلهية بظهور العلوم الحسابية والمنطقية، ويستدرجون بـه ضعفاء العقول، ولو كانت علومهم الإلهية متقنة البراهـين، نقيـة عن التخمسين؛ كعلومهم

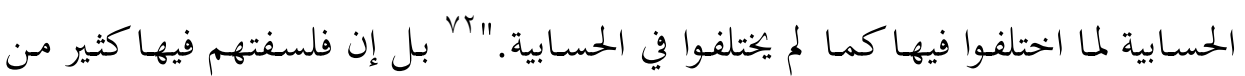
الخداع والتلبيس والتخييل. VT

ويقـرر الغزالي أنسه مُّا زاد الطين بِلَّةً تحريـف مـا تُرجِم عن فلاسفة اليونـان، وبخاصـة

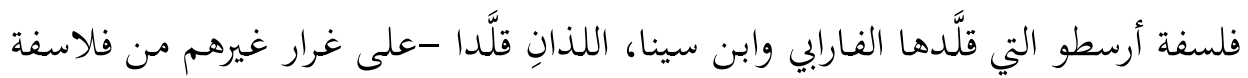
المشّيّئية المسـلمين - أرسطو في مفاسـده وضـلالاته. يقـول في ذلك: "ثم المترجمون لكالام أرسطاطاليس لم ينفـك كلامهـم عن تحريـف وتبـديل محوج إلى تفسير وتأويل، حستى أثنار ذلك أيضاً نزاعاً بينهم. "V "v وبسبب كل المفاسد المنتشرة في تلك الآراء الفلسفية جميعها؛ فقد أكَّد الغزالي الخلل الكبير الذي تتضمَّنه الآراء والأفكار الخاصة بفلاسفة اليونان ومَن.

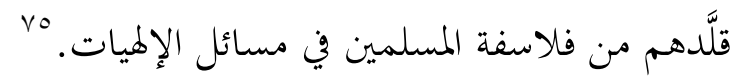

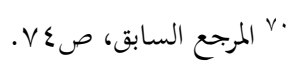

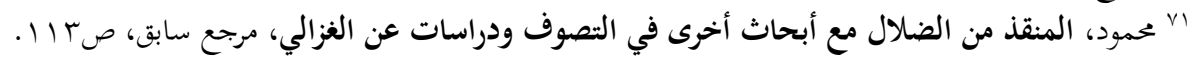

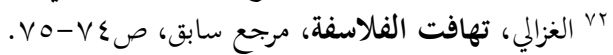

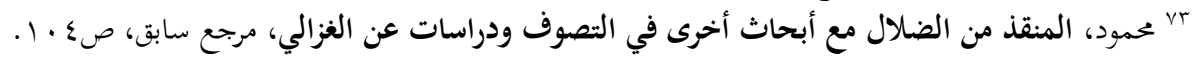

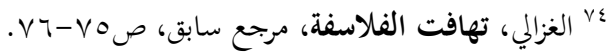

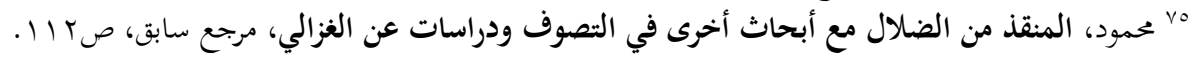




\section{ت. نقد دعوى البرهانية في القول المشّائي في الإلهيات:}

يـرى الغـزالي في معـرض رده علـى مَـن ادَّعـى برهانيـة القــول الفلسـفي المشـائي في

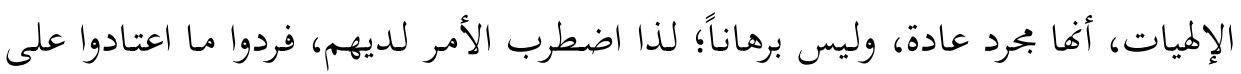

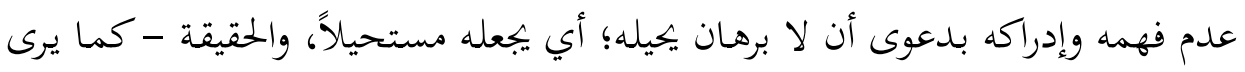

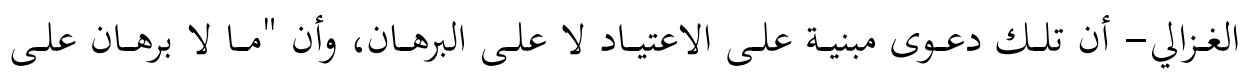

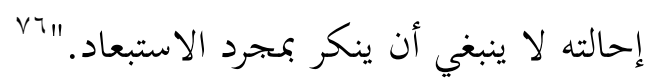

وهـذا منشـأ غلط الفلاسفة؛ لأهـم كمـا يقـول الغزالي: "أكثر بـراهين الفلاسفة في

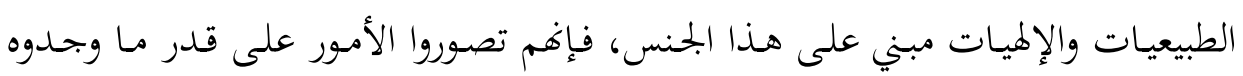

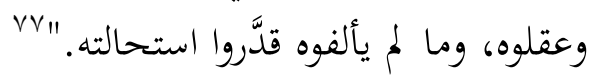

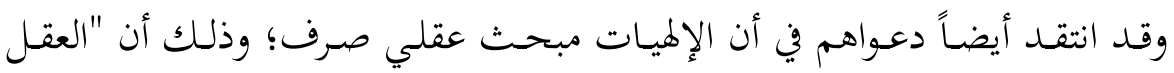

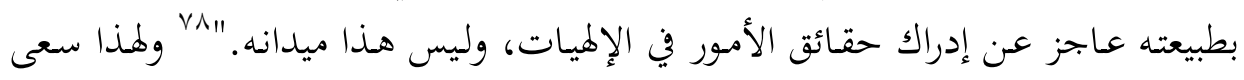

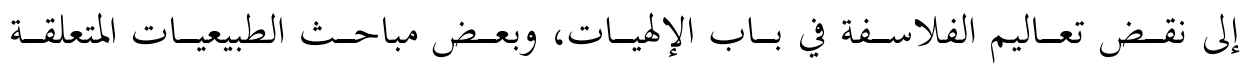

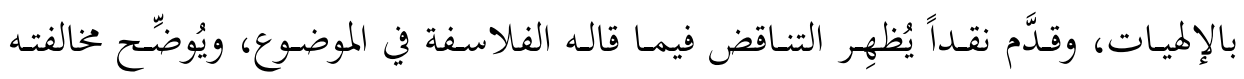

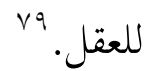

وهو في نقده هذا يُؤسِّ لمنهج خحاص بالمثاقفة الفكرية والفلسفية؛ إذ يقول: "وإذا

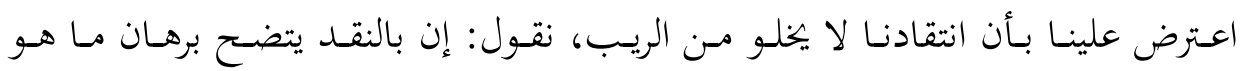

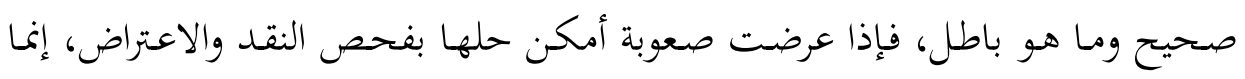

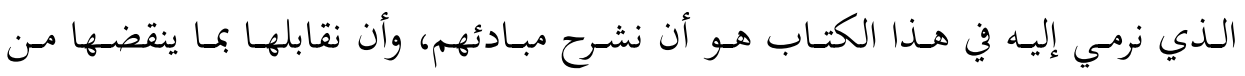

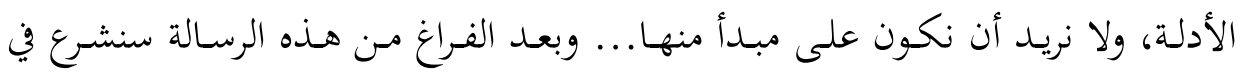

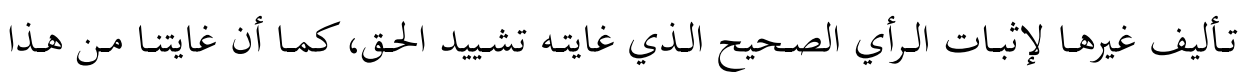

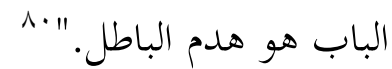

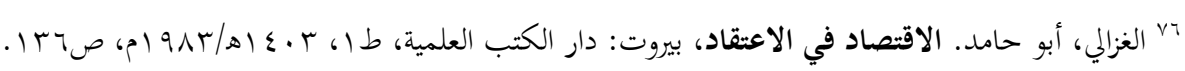

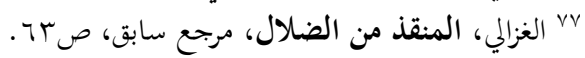

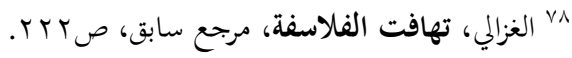

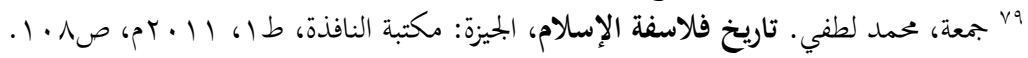

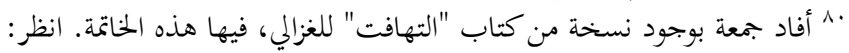




\section{ث. رد الإلهيات وتقريب المنطقيات:}

مـن الواضـح أن هجـوم الغـزالي كـان علـى الميتافيزيقيـا والكسـمولوجيا (الإلهيـات،

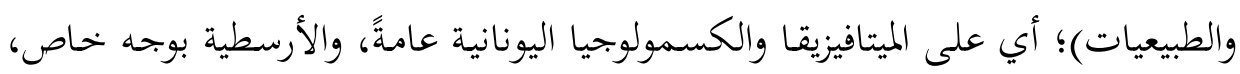

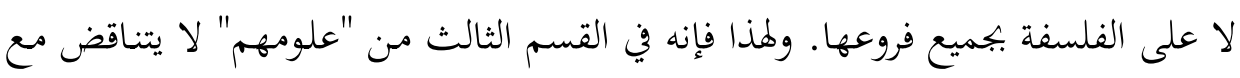

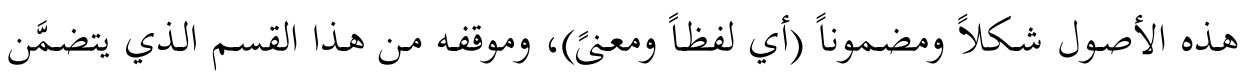
باقي القضايا الفلسفية هو الأخذ والقبول. وفي هذا تدرج الطبيعيات والمنطقيات. وهذا

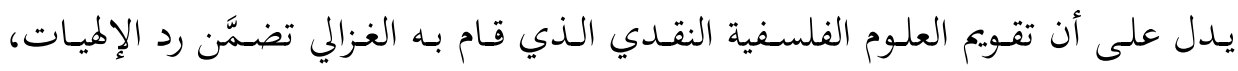

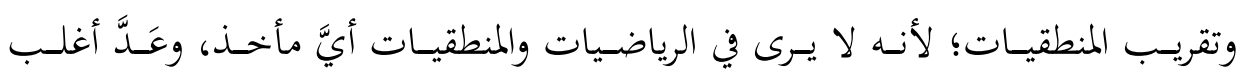

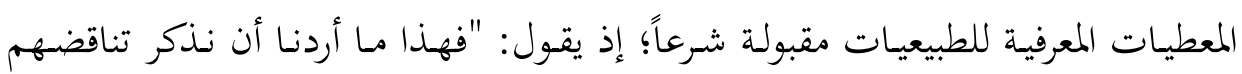

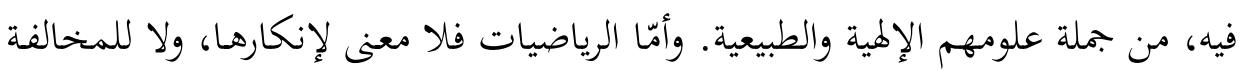

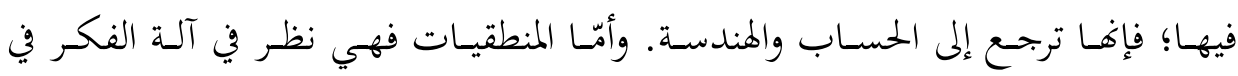

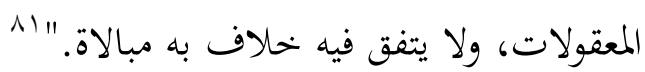

فقد قَّبَ الغزالي المنطقيات لأن "أكثرها على منهج الصواب، والخطأ نادر فيها؛ إذ

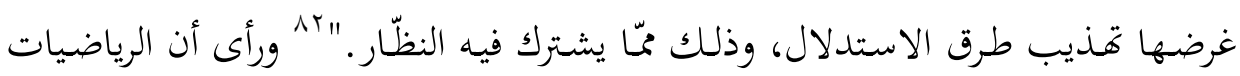

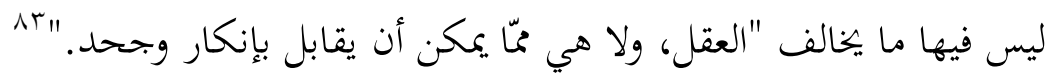
وفي المقابل، وجَّه الغزالي نقده اللاذع إلى الفلسفة بمعناها الخاص؛ أي الإلهيات التي

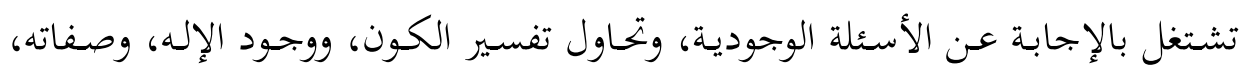

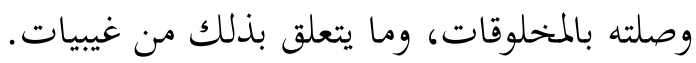

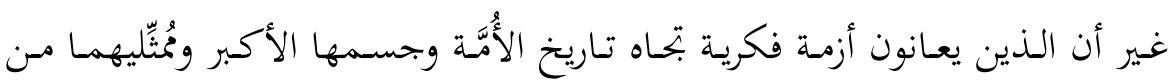

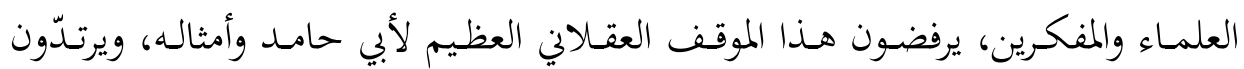

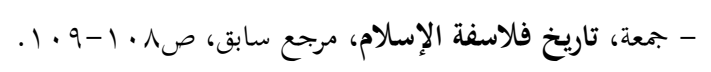

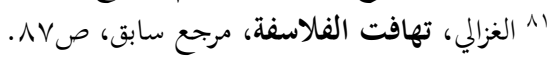

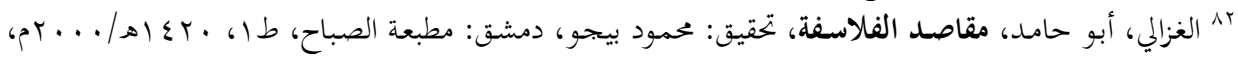




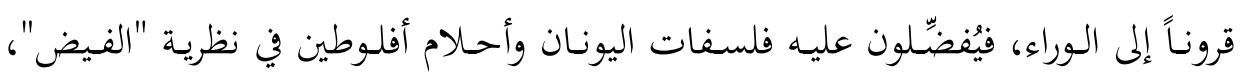

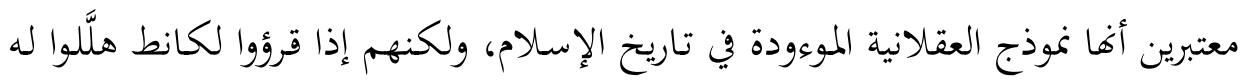

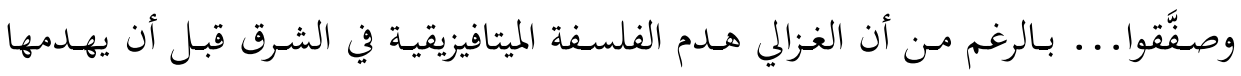
كانط في الغرب. و وصغو

\section{خاتمة:}

أوصلنا هذا البحث في فكر الإمام الغزالي إلى نتائج قيّمة، يمكن إجمالها فيما يأتي: ا ـ إن مثاقفـة الغـزالي الفكريـة مـع الوافـــ الأجنـبي الـمُتمثّل حضـارياً في الفلسـفة

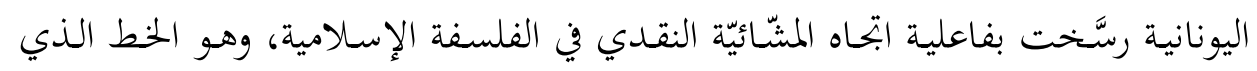

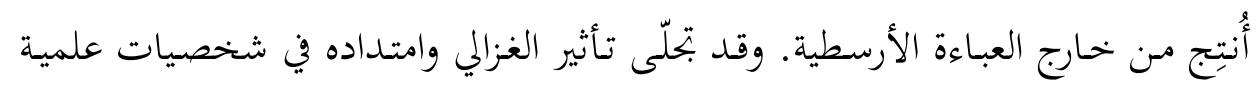
إسلامية ومدارس فكرية حوت الكثير من الرواد، وعلى رأسهم ابن تيمية السلفي، وابن ولني خلدون الاجتماعي.

r ـ إن الخط النقدي الذي أسهم الغزالي إسهاماً فاعلاً في وضع لبناته توجَّهه بالنقد

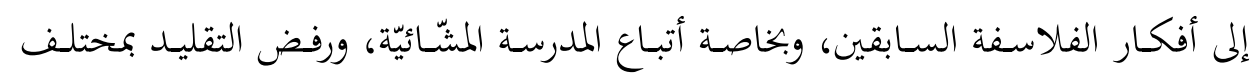

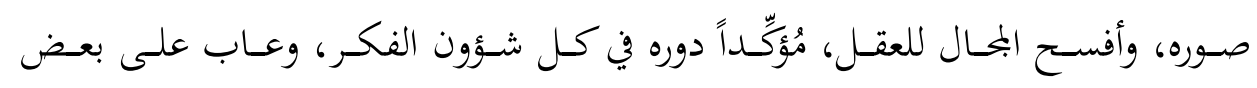

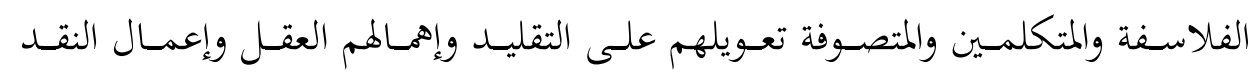

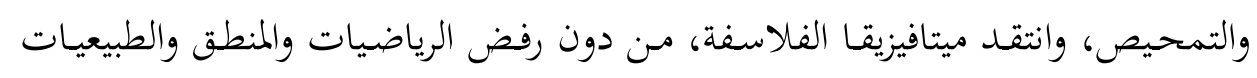

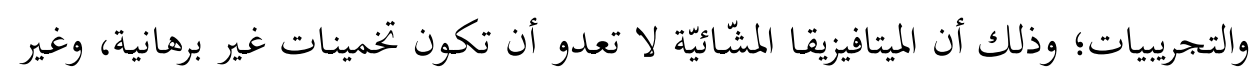

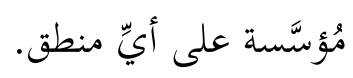

ب. إن الغزالي يُمثّل نموذجاً مُهِمّاً في تراثنا الفكري بحيث نتعلم منه نقد الأفكار بعد

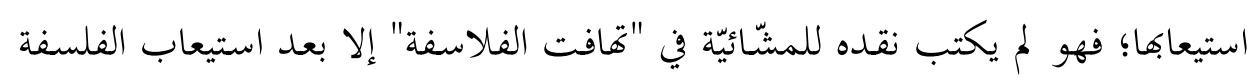

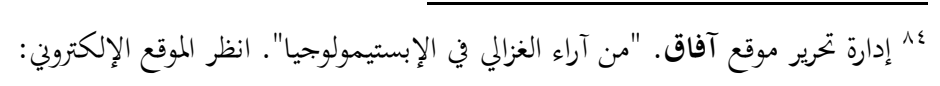

- http://aafaqcenter.com/index.php/post/1377\#story-1 
والمدارس الفلسفية واتحاهات الفلاسفة كما بيَّن ذلك في "المنقذ من الضلال"، و "مقاصد الفلاسفة"؛ إذ أبان عن فهم متكامل للتراث الفلسفي الإغريقي المتداول في ساحة الثقافة

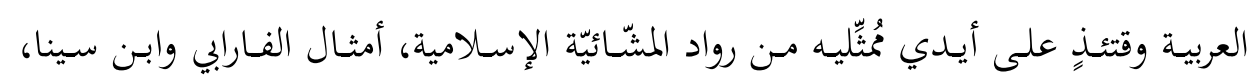
فكان نقده بعد ذلك في "قافت الفلاسفة" نقداً مقتدراً في كثير من جوانبه. ع. إن رفض الفلسفة كلياً في تراثنا من بعض المفكرين، أو تبنّيها كاملاً من بعضهم

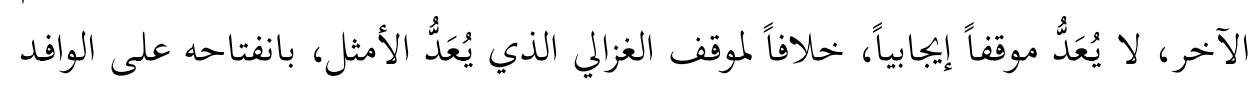

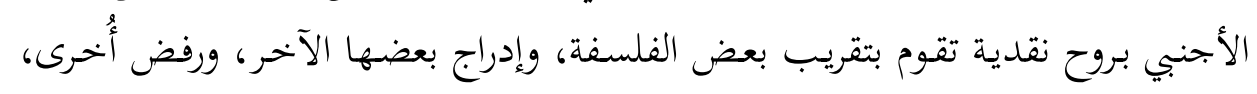

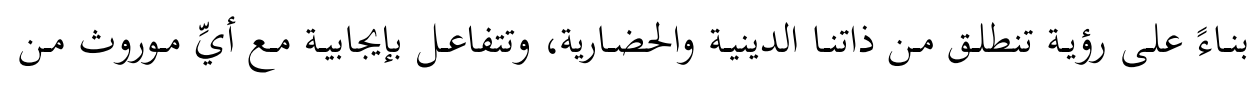
علوم الأوائل أو الأواخر . علئ.

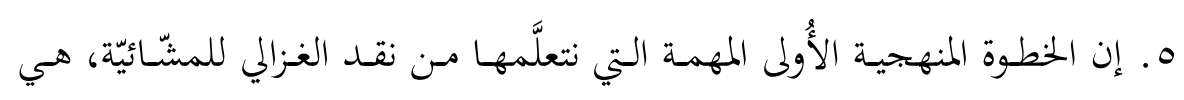

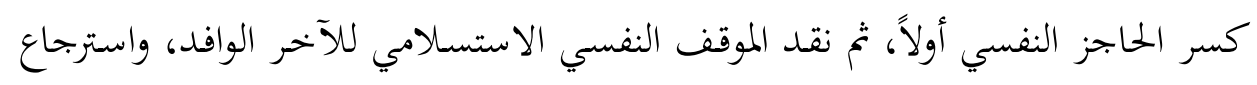
الشعور بالأنا الديني والحضاري؛ ذلك أن عقدة النقص والدونية بجعل المصاب بها مُقِبِالًا على كل ما يفيد من دون تمحيص. ولهذا، فإن استرجاع الشعور بالذات المتميّزة يمنحنا

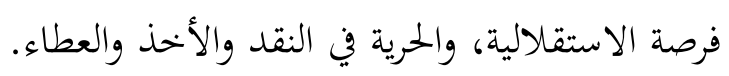

I . استلهام موقف نقدي للتراث الفلسفي الحديث والمعاصر مـ التجربة الفلسفية

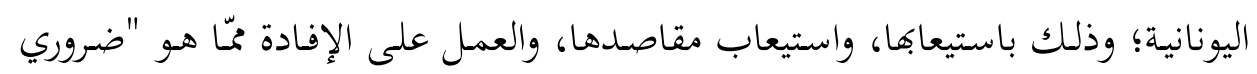
للنوع"، واستبعاد "هافته"، و "وجودياته"، وبحاوزه إلى إضافات أكثر إنسانيةً وعلميةً. 